\title{
Multiband FSS Analysis and Synthesis Based on Parallel Non Coupled Metallic Strips Using WCIP Method
}

\author{
Karima Bencherif ${ }^{1}$, Mohammed Titaouine ${ }^{1,2}$, Raouia Saidi $^{1}$, Awatef Djouimaa ${ }^{1}$, Ibtissem Adoui ${ }^{2}$, \\ Thayuan Rolim De Sousa ${ }^{3}$, Alfredo Gomes Neto ${ }^{3}$, Henri Baudrand ${ }^{4}$ \\ ${ }^{1}$ Department of Electronics, Faculty of Technology, University of Batna 2 (Mostefa Ben Boulaïd), Batna \\ 05000, Algeria \\ ${ }^{2}$ Laboratory of Materials and Electronic Systems LMSE, Faculty of Sciences and Technology University of \\ Bordj Bou Arreridj, University, El Anasseur 34625, Algeria \\ bencherifka@gmail.com, mohammedtitaouine@gmail.com, \\ saidiraouia@gmail.com, awatefdjouimaa@gmail.com,ibtissem.adoui@gmail.com \\ ${ }^{3}$ Group of Telecommunications and Applied Electromagnetism, GTEMA, Federal Institute of Education \\ Science and Technology of Paraiba, IFPB, Av. 1 de Maio, 720, Joao Pessoa, PB, CEP 58015-430, Brazil \\ thayuan.rolim@gmail.com, alfredogomesjpa@gmail.com \\ ${ }^{4}$ University of Toulouse; INPT, UPS; LAPLACE; ENSEEIHT, 2 Rue Charles Camichel, Toulouse Cedex 7, BP \\ 7122, F-31071, France \\ henri.baudrand@yahoo.fr
}

\begin{abstract}
A novel parallel non coupled metallic strips frequency selective surface (FSS) is presented. The design is based on a filter composed of horizontal and vertical metallic strips. The structure has the advantage of simplicity and gives multi resonant frequencies easily controlled by a simple variation in the strips length. The proposed FSS rejects frequencies at $7 \mathrm{GHz}, 9.4 \mathrm{GHz}$ with bandwidths of $0.646 \mathrm{GHz}, 0.793 \mathrm{GHz}$ respectively when the structure is excited with an $x$ polarized plane wave, and two frequencies at $9.1 \mathrm{GHz}$ and $11.2 \mathrm{GHz}$ with bandwidth of $280.3 \mathrm{MHz}$, $63 \mathrm{MHz}$ respectively when the structure is excited with a $y$ polarized plane wave. To suppress frequencies ideal diode on reverse bias are inserted. The simulated results obtained using WCIP (Wave Concept Iterative Method) are compared to the COMSOL Multiphysics 4.3b software results, and measurements, a good agreement is observed. Then, an FSS synthesis approach based on non coupled parallel metallic strips is presented. It provides synthesized FSS with resonant frequencies ranging from $4.5 \mathrm{GHz}$ and $12.25 \mathrm{GHz}$ for metallic strips lengths inversely varying from $5 \mathrm{~mm}$ to $19 \mathrm{~mm}$. To validate the synthesis approach, measured resonant frequencies are used as desired resonant frequencies to determine the metallic strips lengths. As a result the metallic strips FSS dimensions are extracted. At this stage the WCIP method is used to characterize the synthesized FSS. Three FSSs are synthesized based on the fabricated FSS and good agreement between measurements and synthesized FSSs results is recorded.
\end{abstract}

Index Terms - WCIP method, FSS structures, Coupling, PIN diodes, tuned resonant frequencies. 


\section{INTRODUCTION}

Frequency selective surface (FSS) is a 2D-periodic planar structure consisting of one or more patches or slots etched on a dielectric substrate to operate as band stop or band pass filters respectively [1-3].

Over the years the FSS was widely investigated for a variety of applications as frequency filters ranging from microwave systems in high performance reflector antenna systems, or advanced radome designs, to infrared devices and optical signals [4-6]. The bandwidths performances are one of the important subjects of researches, with the diversity of the wireless communications systems and the increase of the number of users. Having structures with multi band applications has become a necessity. The FSS frequency response depends on several factors: the incident wave polarization, the substrate thickness and permittivity, the spacing between the element, and the choice of the elements geometry which is the important one [7].

In this paper the analysis of simple FSS based on parallel non coupled metallic strips using WCIP (Wave Concept Iterative Method) is presented. The structure has two resonant frequencies when the structure is excited with an $x$-polarized plane wave and also two resonant frequencies when the structure is excited with a $y$-polarized plane wave. The effect of the metallic strips lengths and strips spacing on the resonance frequencies is studied. The parametric study results in a determination of metallic strips minimum spacing to provide strips decoupling. Frequency tenability is obtained by varying the strips lengths. Another method often used to obtain a variable FSS frequency response is the use of inversely biased PIN diodes to switch the FSS diodes between the ON and the OFF states [7].

The WCIP results are compared to the COMSOL Multiphysics $4.3 \mathrm{~b}$ software results, and the measurements, a good agreement is observed.

For a priory choice of the FSS resonant frequencies number and values based on the available substrates, a synthesis approach based on non coupled parallel metallic strips and a ring is introduced. First the characteristic strip/ring curve is determined using the WCIP method for strip lengths ranging from $6 \mathrm{~mm}$ to $19 \mathrm{~mm}$ and for the ring outer circumference varying from $34 \mathrm{~mm}$ to $58 \mathrm{~mm}$. To validate the presented synthesis approach, measured resonant frequencies of three manufactured FSSs are input to the proposed approach as desired resonant frequencies to extract the necessary metallic strips lengths. Thus all the metallic strips FSS dimensions are determined. To analyze the synthesized FSS the WCIP method is used. The presented synthesis approach allows also the determination of an equivalent metallic strips based FSS for complexes FSS structures. Good agreement between measurements and WCIP results obtained for the synthesized FSSs is observed. 


\section{WCIP FORMULATION}

The simplicity of the WCIP procedure is based on Fast Modal Transform (FMT) switching between spatial and spectral domain and the convergence is insured independently of the circuit complexity [8$10]$.

In the WCIP method the FSS analysis is reduced to that of the unit cell limited by periodic walls shown as dashed lines in Fig. 1. The FSS unit cell is composed of two domains corresponding to the metal domain and the dielectric domain as shown in Fig. 1.

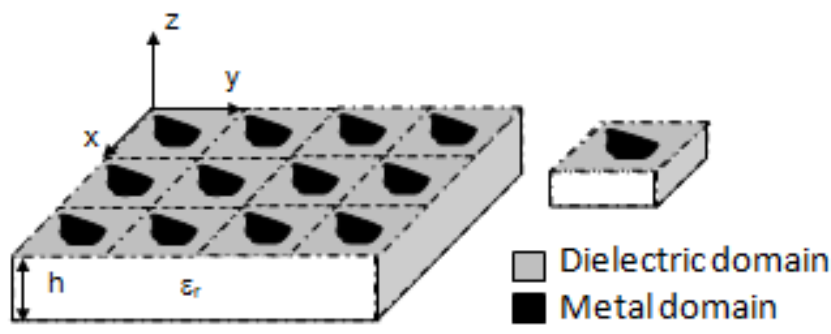

(a)

(b)

Fig. 1. (a) Geometry of arbitrary FSS (b) Unit cell in the FSS structure.

The incident waves $\vec{A}_{i}$ on the FSS unit cell and reflected waves $\vec{B}_{i}$ from the FSS unit cell are described at the boundaries interfaces as a function of the tangential electric field $\overrightarrow{\mathrm{E}}_{\mathrm{Ti}}$ and the transverse electric current densities $\vec{J}_{\mathrm{i}}$ as [11],[12]:

$$
\begin{aligned}
& \overrightarrow{\mathrm{A}}_{\mathrm{i}}=\frac{1}{2 \sqrt{\mathrm{Z}_{0 \mathrm{i}}}}\left(\overrightarrow{\mathrm{E}}_{\mathrm{Ti}}+\mathrm{Z}_{0 \mathrm{i}}\left(\overrightarrow{\mathrm{H}}_{\mathrm{Ti}} \wedge \overrightarrow{\mathrm{n}}\right)\right) \\
& \overrightarrow{\mathrm{B}}_{\mathrm{i}}=\frac{1}{2 \sqrt{\mathrm{Z}_{0 \mathrm{i}}}}\left(\overrightarrow{\mathrm{E}}_{\mathrm{Ti}}-\mathrm{Z}_{0 \mathrm{i}}\left(\overrightarrow{\mathrm{H}}_{\mathrm{Ti}} \wedge \overrightarrow{\mathrm{n}}\right)\right) \\
& \text { With: } \overrightarrow{\mathrm{J}}_{\mathrm{i}}=\overrightarrow{\mathrm{H}}_{\mathrm{Ti}} \wedge \overrightarrow{\mathrm{n}}
\end{aligned}
$$

$\overrightarrow{\mathrm{H}}_{\mathrm{Ti}}$ is the transverse magnetic field, $Z_{0 i}$ represents the wave impedance of the middle $i,(i$ is the medium index $(i=1,2))$, and it is expressed as: $Z_{0 i}=\sqrt{\mu_{0} / \varepsilon_{i} \varepsilon_{0}}$.

The diffracted waves $\vec{B}_{i}^{(k)}$ at the $k^{\text {th }}$ iteration are obtained from the incident waves $\vec{A}_{i}^{(k)}$ by [13]:

$$
\overrightarrow{\mathrm{B}}_{\mathrm{i}}^{(\mathrm{k})}=\widehat{\mathrm{S}}_{\Omega} \overrightarrow{\mathrm{A}}_{\mathrm{i}}^{(\mathrm{k})}
$$

$\widehat{\mathrm{S}}_{\Omega}$ is the diffraction operator at the interface $\Omega$ containing the FSS circuit and it is defined in the spatial domain. It is determined from the geometry of the planar unit cell and the boundary conditions at the interface [14].

The diffracted waves are projected into periodic wall rectangular wave guide modes basis (TEM mode, TE modes and TM modes) making a complete modal basis. Each resulting mode propagates independently of the all the other modes since they are uncoupled in the modal domain. Thus each 
mode is reflected with a specific reflection coefficient [15] at the dielectric medium discontinuity made by the substrate and the air due to the hypothetical rectangular waveguide's modes closing impedances. Thus the reflection operator in defined in the modal domain $\hat{\Gamma}_{\mathrm{i}}$.

The reflected waves are equal $\widehat{\Gamma}_{\mathrm{i}} \mathrm{B}_{\mathrm{i}}^{(\mathrm{k})}$ and the next iteration incident waves $\overrightarrow{\mathrm{A}}_{\mathrm{i}}^{(\mathrm{k}+1)}$ of the $(\mathrm{k}+1)^{\text {th }}$ iteration is obtained by adding the wave source $\overrightarrow{\mathrm{A}}_{0}$ to the reflected waves [13] as:

$$
\overrightarrow{\mathrm{A}}_{\mathrm{i}}^{(\mathrm{k}+1)}=\widehat{\Gamma}_{\mathrm{i}} \mathrm{B}_{\mathrm{i}}^{(\mathrm{k})}+\overrightarrow{\mathrm{A}}_{0}
$$

Where $\widehat{\Gamma}_{\mathrm{i}}$ is the reflection operator defined in the modal domain.

The fast modal transform (FMT) and its inverse $\left(\mathrm{FMT}^{-1}\right)$ necessary at each iteration and given in $[13,16,17,18]$ allows the transition from the spatial domain to the modal domain and vice versa as:

$$
\begin{aligned}
& \mathrm{B}_{\text {Modal }}=\mathrm{FMT}\left(\mathrm{B}_{\text {Spatial }}\right) \\
& \mathrm{A}_{\text {spatial }}=\mathrm{FMT}^{-1}\left(\mathrm{~A}_{\text {Modal }}\right)
\end{aligned}
$$

The iterative procedure is repeated until convergence of the input admittance $Y_{\text {in }}$ is obtained. The WCIP method's convergence is ensured independently of the analyzed structure due to bounded reflection operator.

The tangential electric and magnetic fields can be calculated from the diffracted waves and the reflected waves as [16]:

$$
\begin{aligned}
& \overrightarrow{\mathrm{E}}_{\mathrm{i}}=\sqrt{\mathrm{Z}_{0 \mathrm{i}}}\left(\overrightarrow{\mathrm{A}}_{1}+\overrightarrow{\mathrm{B}}_{\mathrm{i}}\right) \\
& \overrightarrow{\mathrm{J}}_{\mathrm{i}}=\left(1 / \sqrt{\mathrm{Z}_{0 \mathrm{i}}}\right)\left(\overrightarrow{\mathrm{A}}_{\mathrm{i}}-\overrightarrow{\mathrm{B}}_{\mathrm{i}}\right)
\end{aligned}
$$

\section{Filter CONFIGURATION}

Initially, the FSS arrangement shown in Fig. 2 is presented to obtain dual polarized multiband FSS structures with patterns offering easy comprehended resonances sources via simple equivalent LC circuits. The linear metallic strip FSS comes to bring this advantage, but the strips coupling affects all the resonances if the length of one strip is altered. To overcome this drawback many simulations are achieved during the parametric study to end with strips spacing resulting in non coupled metallic strips FSS structures. Hence, the resulted FSS is made of linear metallic strips independent in both the spatial domain and the spectral domain. The choice of the strips lengths is made in such a way to obtain resonances in the frequency range that can be measured at the GTEMA/CEFET-PB laboratory of Brazil being less than $14 \mathrm{GHz}$. Other experimental limitations are the substrate thickness being 
chosen to be $1 \mathrm{~mm}$ since the available substrates at the laboratory are those with thicknesses of $0.8 \mathrm{~mm}$, $1 \mathrm{~mm}$, and $1.5 \mathrm{~mm}$ and a dielectric constant of 4.4 because it is made of fiber glass (FR-4), in addition to cell dimensions fixed to be $20 \mathrm{~mm} \times 20 \mathrm{~mm}$.

The filter configuration is presented in Fig. 2.a. The structure is fabricated from copper and etched on a $1 \mathrm{~mm}$ thickness substrate with relative dielectric constant of 4.4. The geometrical dimensions of the proposed FSS unit cell shown in Fig. 2.b have the following values: $a=b=20 \mathrm{~mm}, L_{1}=9.61 \mathrm{~mm}$, $L_{2}=7.532 \mathrm{~mm}, \quad L_{3}=13.684 \mathrm{~mm}, L_{4}=9.736 \mathrm{~mm}, W_{1}=0.789 \mathrm{~mm}, \quad W_{2}=0.779 \mathrm{~mm}$, and $d_{1}=5.263 \mathrm{~mm}$, $d_{2}=3.376 \mathrm{~mm}, d_{\mathrm{x}}=2.7 \mathrm{~mm}, d_{\mathrm{y}}=1.8 \mathrm{~mm}$.

The FSS structure is excited with an $x$ and $y$ polarized normal incident plane waves. The WCIP results are compared to the simulated results, and the measurements .The experimental results are done on FSS of arrays consisting of $10 \times 10$ unit cells as shown in Fig. 2.a.

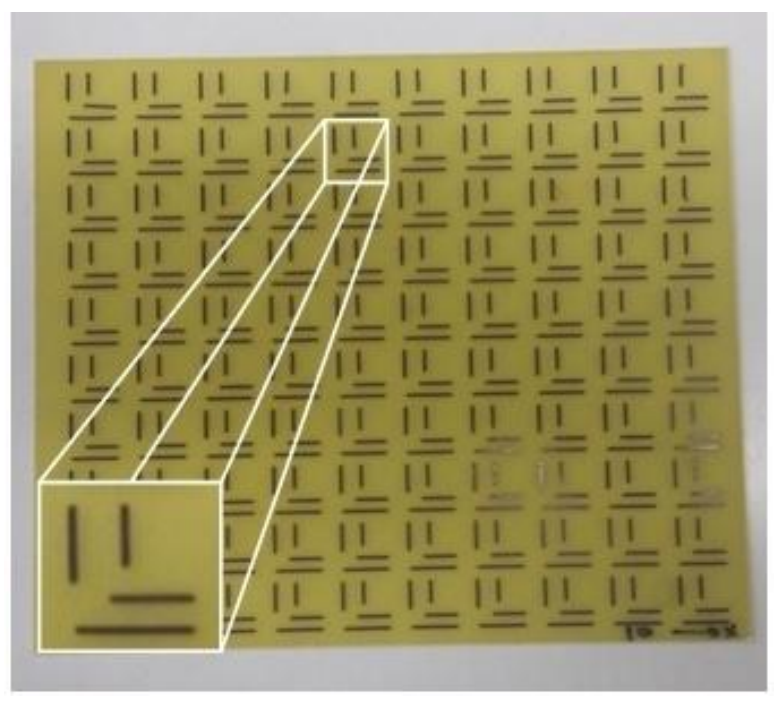

(a)

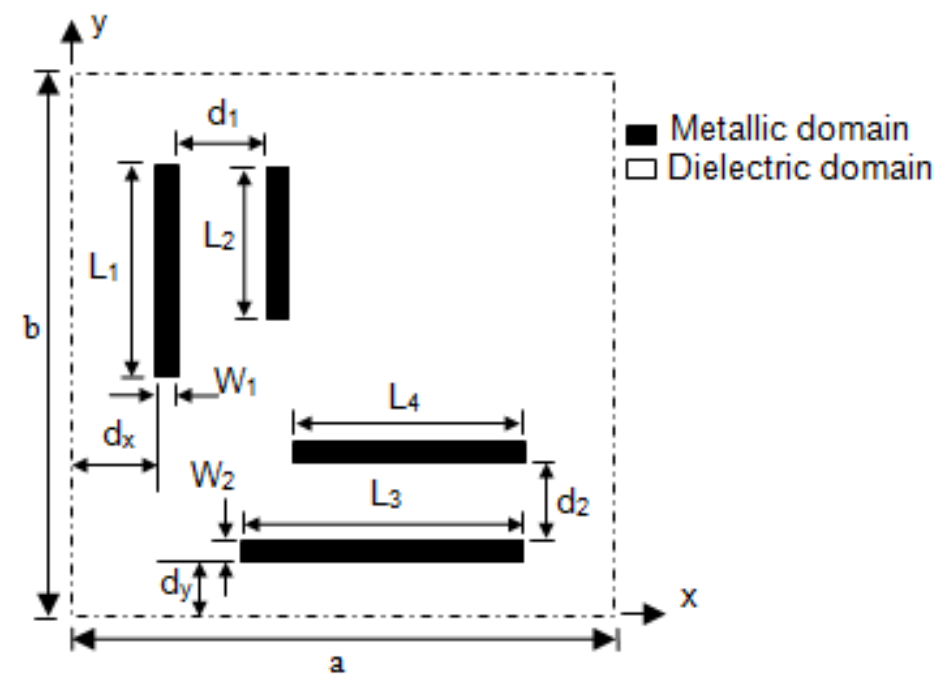

(b)

Fig. 2. The parallel metallic strips FSS: (a) Realized FSS with an array of 10unit cells and (b) FSS unit cell geometry.

\section{RESULTS AND DISCUSSION}

The FSS unit cell interface of Fig. 2.b is described by $200 \times 200$ pixels and the iterative process is stopped after 350 iterations.

The WCIP results are validated by comparing them to the simulated results and the experimental results.

The transmission coefficients $S_{12}$ of the parallel metallic strips FSS of Fig. 2 when the structure is excited by an $x$ and $y$ polarized normal plane waves are shown in Figs. 3.a and 3.b respectively. The simulated and measured results show a good agreement.

As shown in Fig. 3 the structure presents two resonant frequencies at about $7.1 \mathrm{GHz}$ and $9.4 \mathrm{GHz}$ with bandwidths of $0.646 \mathrm{GHz}, 0.793 \mathrm{GHz}$ at $-10 \mathrm{~dB}$ respectively when it is excited with an $x$ polarized plane wave, and two resonant frequencies at about $9.1 \mathrm{GHz}$ and $11.2 \mathrm{GHz}$ with bandwidths of 
280.3MHz, $63 \mathrm{MHz}$ respectively when the structure is excited with a $y$ polarized plane wave.

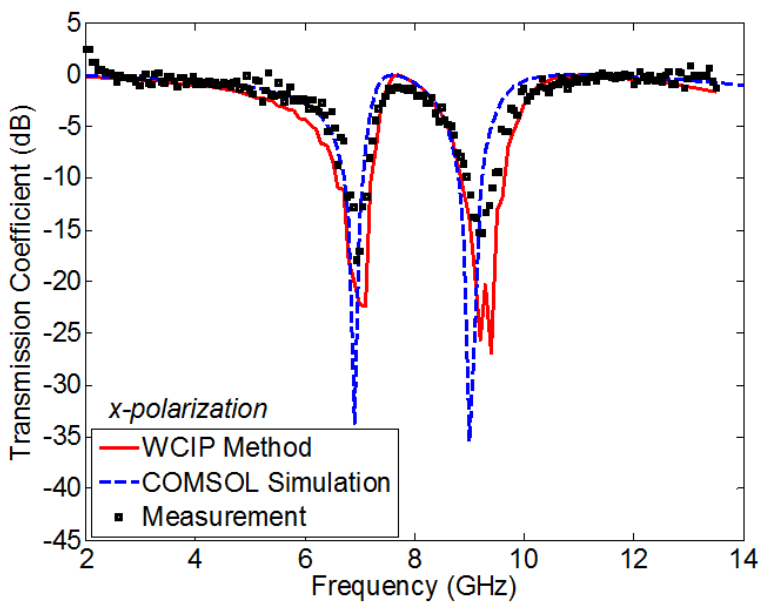

(a)

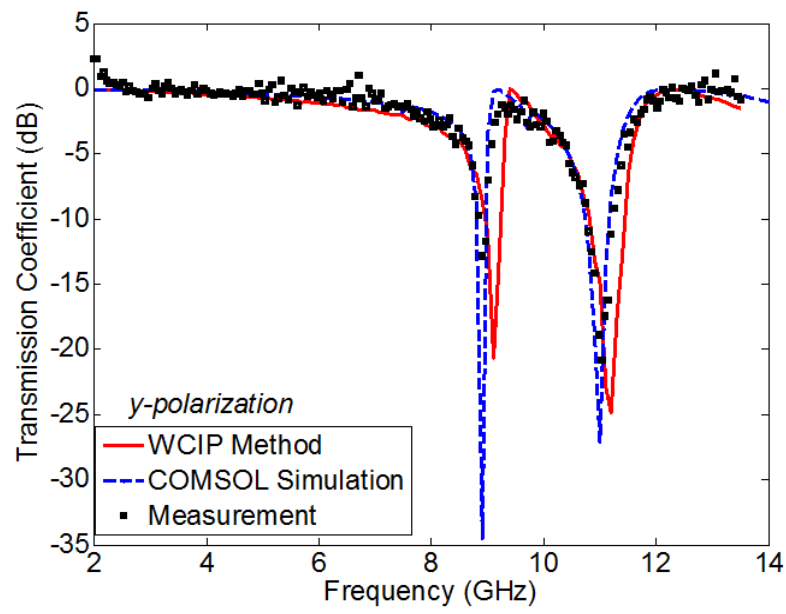

(b)

Fig. 3. Simulated and measured transmission coefficient for the : (a) $x$ polarization - (b) $y$ polarization.

\section{A. Metallic strips coupling effect study}

To study the metallic strips coupling effect of the structure shown in Fig. 2 one strip at a time is eliminated to lead to a structure with three strips. Figs. 4.a and 4.b present the transmission coefficient of the four possible structures. Figs. 3.a and 3.b respectively shows that the elimination of a metallic strip results in an elimination of its corresponding resonance without altering the other resonances created by the remaining strips. Thus there is no coupling between the strips of the proposed structure in Fig. 2.

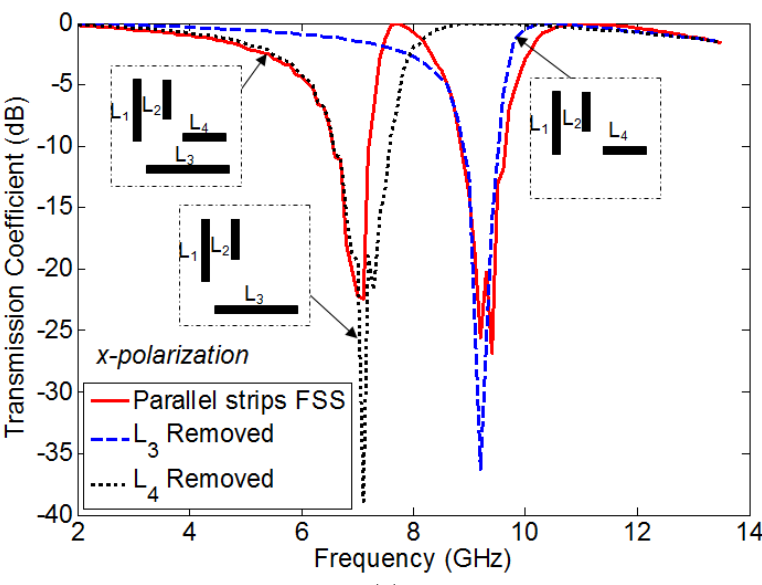

(a)

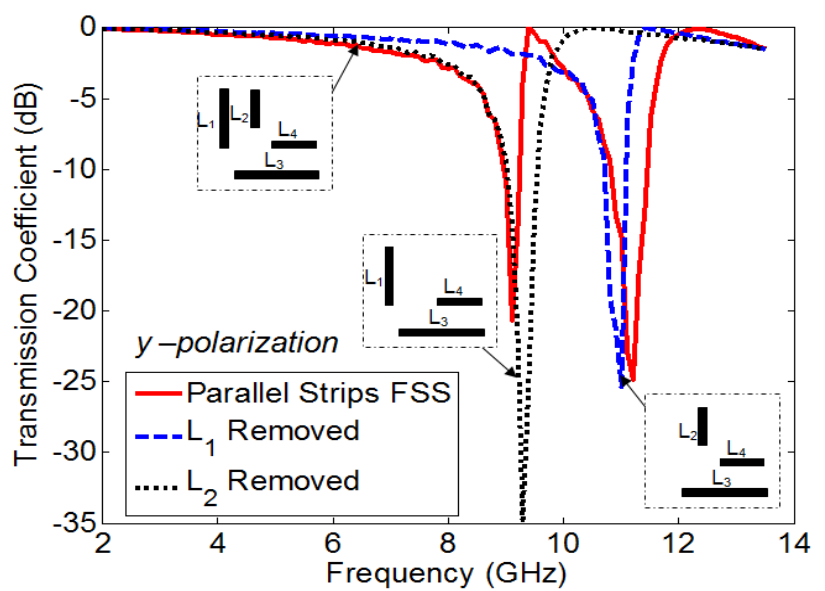

(b)

Fig. 4. Simulated and measured transmission coefficient for the : (a) $x$ polarization - (b) $y$ polarization.

\section{B. Frequencies tenability}

The two resonant frequencies characterizing the FSS structure of Fig. 2.b and excited with an $x$ polarized plane wave source are adjusting by a variation in the strips dimensions $L_{3}$ and $L_{4}$.

The decrease of $L_{3}$ from $13.684 \mathrm{~mm}$ to $11.684 \mathrm{~mm}$ allows the increase of the lowest resonance frequency from $7 \mathrm{GHz}$ to $7.8 \mathrm{GHz}$ as shown in Figs. 5.a and 5.b. The increase of the second resonant 
frequency from $9.4 \mathrm{GHz}$ to $10 \mathrm{GHz}$ is observed when $L_{4}$ decreases from $9.736 \mathrm{~mm}$ to $8.736 \mathrm{~mm}$ respectively as shown in Fig. 6.a and 6.b. The obtained WCIP method results are compared to the simulated results, and a good agreement is reported.

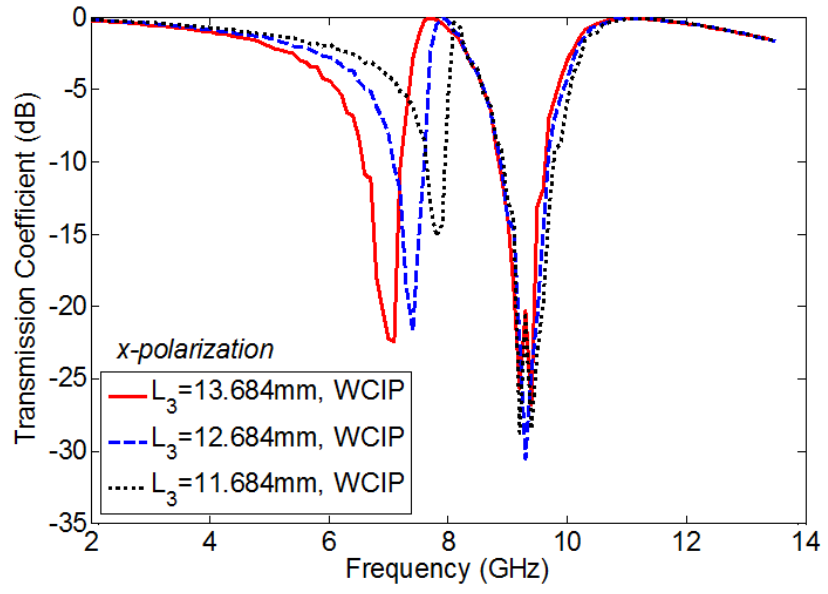

(a)

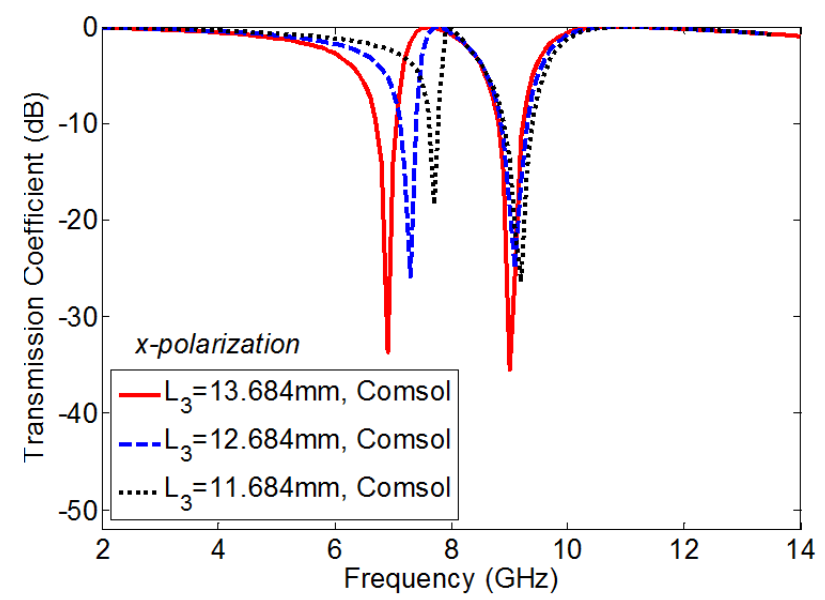

(b)

Fig. 5. Transmission coefficient versus frequency for different Values of $L_{3}$ for the $x$ polarization : (a) WCIP results - (b) Simulated results.

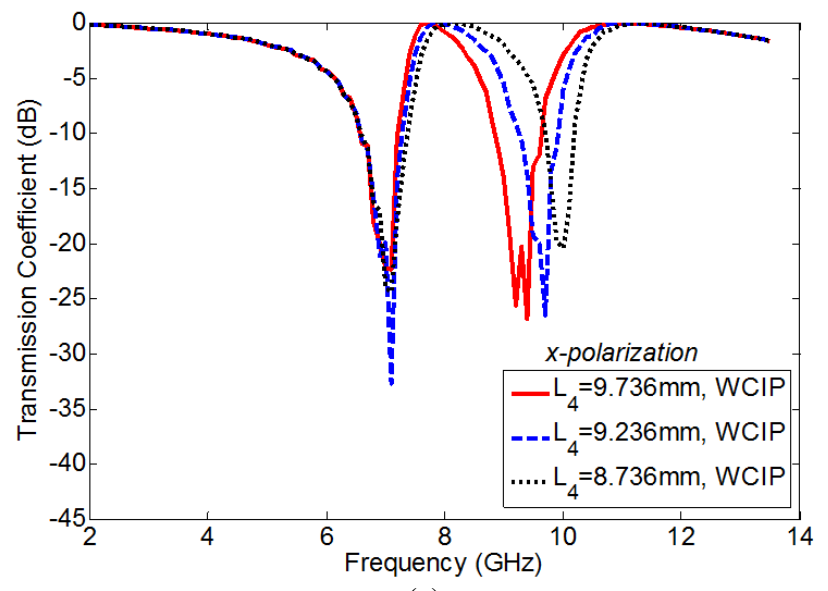

(a)

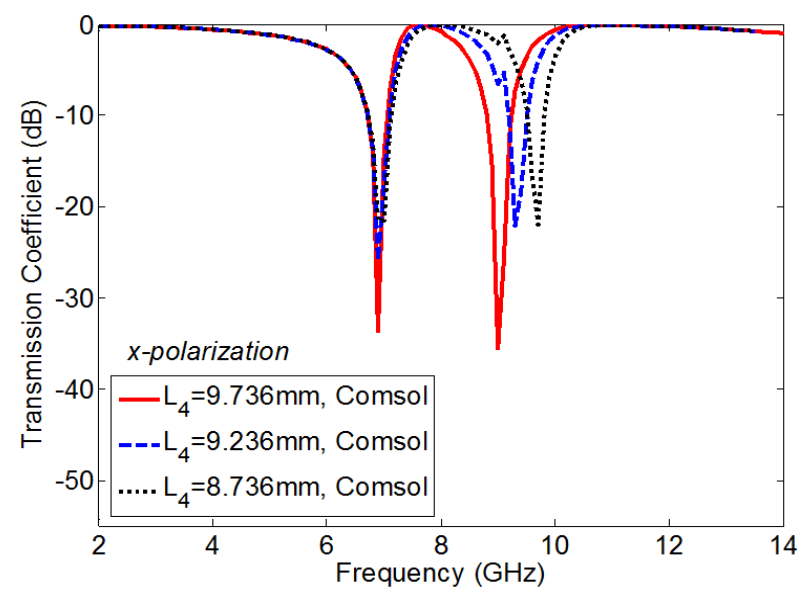

(b)

Fig. 6. Transmission coefficient versus frequency for different Values of $L_{4}$ for the $x$ polarization : (a) WCIP results - (b) Simulated results.

In the case of the $y$-polarized source, the two resonant frequencies are tuned by the variation of the parallel strips dimensions $L_{1}$ and $L_{2}$, the increase of the lowest resonance frequency from $9.1 \mathrm{GHz}$ to 9.7 GHz is achieved by the decrease of $L_{1}$ from $9.61 \mathrm{~mm}$ to $8.61 \mathrm{~mm}$ as shown in Figs. 7.a and 7.b.

The increase of the higher resonant frequency from $11.2 \mathrm{GHz}$ to $11.9 \mathrm{GHz}$ is observed when $L_{2}$ decreases from $7.532 \mathrm{~mm}$ to $6.532 \mathrm{~mm}$ as shown in Figs. 8.a and 8.b.

Hence the different resonant frequencies can be independently controlled by only varying the strips lengths $L_{1}, L_{2}, L_{3}, L_{4}$. Moreover the resonances can be separately eliminated by only removing the strip responsible of the resonance. The simulated results obtained using WCIP are compared to the simulated results and a good agreement is reported. 


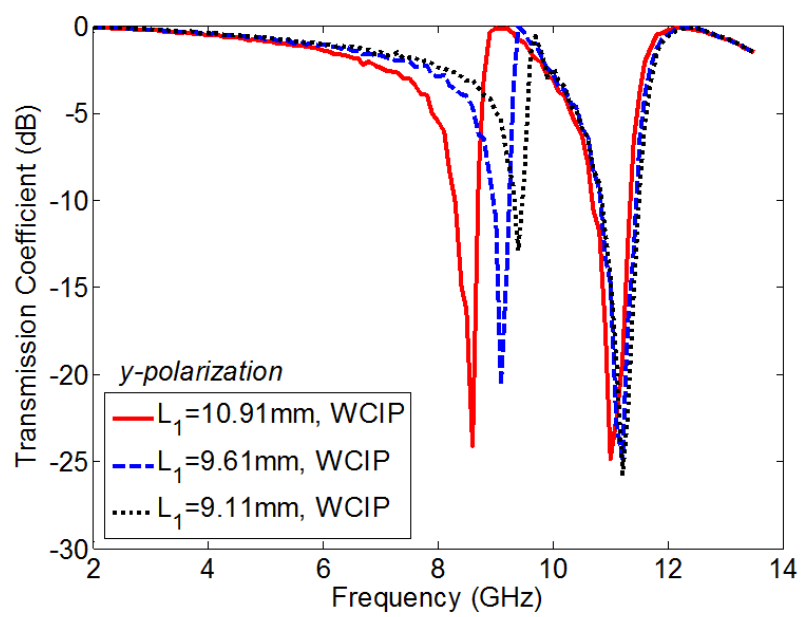

(a)

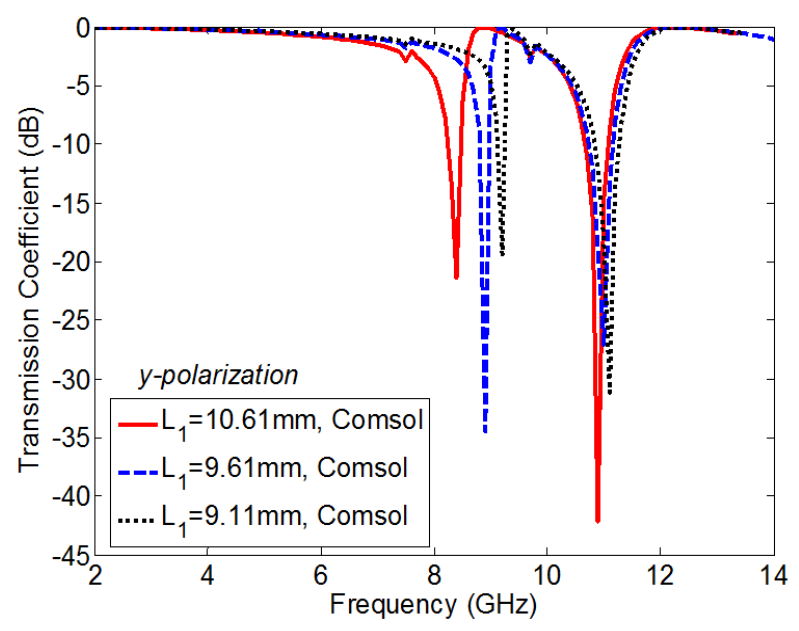

(b)

Fig. 7. Transmission coefficient versus frequency for different Values of $L_{1}$ for the $y$ polarization : (a) WCIP results - (b) Simulated results.

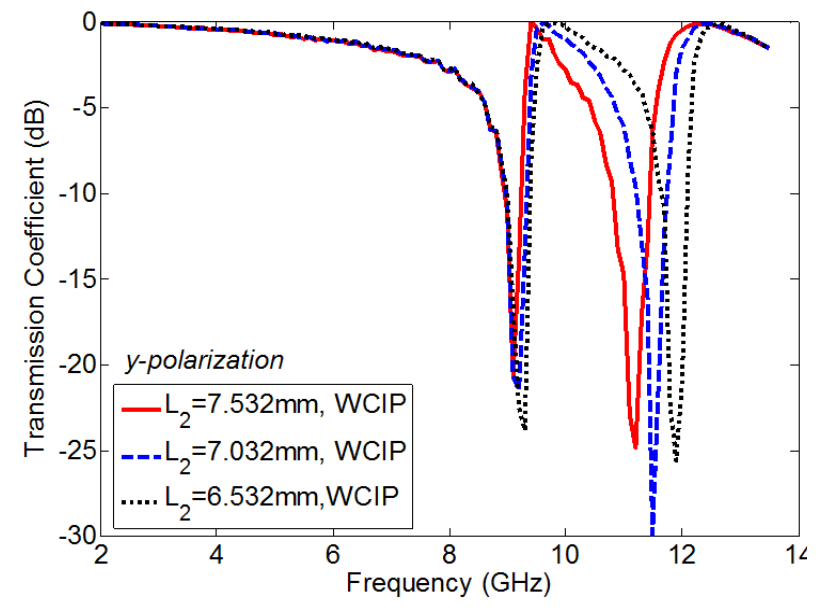

(a)

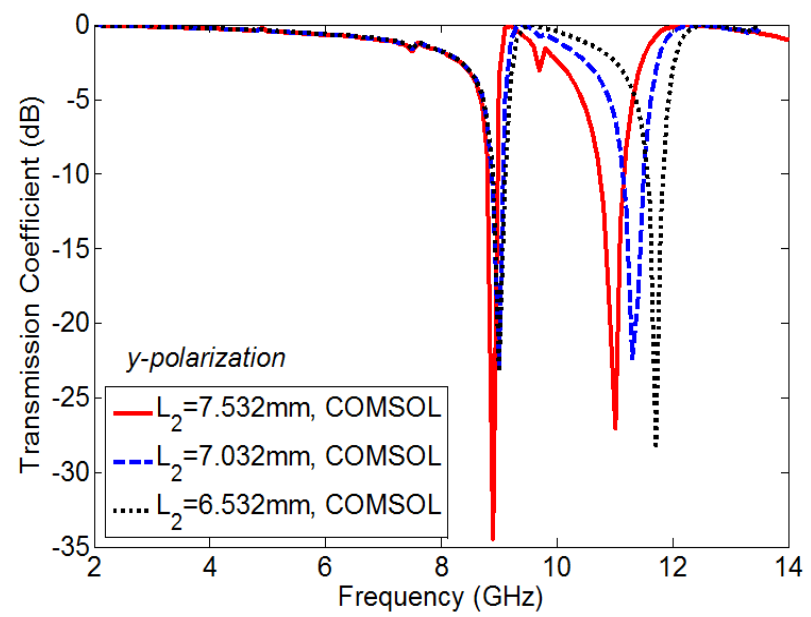

(b)

Fig. 8. Transmission coefficient versus frequency for different Values of $L_{2}$ for the $y$ polarization : (a) WCIP results - (b) Simulated results.

The resonant frequency of a linear metallic strip FSS simulated by the WCIP method and calculated also by equations (10) and (11) [19-21] is given in Table I for different strip lengths.

$$
\begin{aligned}
& \mathrm{f}_{\mathrm{r}}=\frac{\mathrm{c}}{2 \mathrm{~L} \sqrt{\varepsilon_{\mathrm{eff}}}} \\
& \varepsilon_{\text {reff }}=\left(\frac{\varepsilon_{\mathrm{r}}+1}{2}\right)
\end{aligned}
$$

TABLE I. ERROR PERCENT OF THE RESONANT FREQUENCIES CORRESPONDING TO THE METALLIC STRIP $L_{3}$

\begin{tabular}{cccc}
\hline $\mathbf{L}_{\mathbf{3}}(\mathbf{m m})$ & $\begin{array}{c}\text { Resonant frequencies WCIP } \\
\text { Method }\end{array}$ & $\begin{array}{c}\text { Resonant frequencies } \\
\text { (Equation 10) }\end{array}$ & Error \% \\
\hline 13.684 & 7 & 6.67 & 4.71 \\
12.684 & 7.4 & 7.19 & 2.83 \\
11.684 & 7.8 & 7.81 & 0.12 \\
\hline
\end{tabular}


The error rises from the non precise $\varepsilon_{\text {eff }}$ given in equation (11). The resonant frequency of a rectangular metallic ring FSS can be also calculated by equations (10) and (11) by replacing the parameter $2 L$ by the ring outer circumference. Hence in order to determine an FSS metallic strip/ring length resonating at a given resonant frequency, a more precise approach is to be adopted.

\section{Electronically controlled FSS resonant frequencies}

The suppression of one of the resonant frequencies can be achieved by inserting a gap of dimensions $W_{\mathrm{g}} \times L_{\mathrm{g}}=0.779 \mathrm{~mm} \times 1 \mathrm{~mm}$ at the appropriate position along the strip responsible of the corresponding resonant frequency. An ideal ON/OFF switch can be used to design an FSS capable of inserting a resonance or removing it as represented in Figs. 10.a and 10.b. In Fig. 2 the strip of length $L_{3}$ even though divided into two equal strips by inserting an ON/OFF switch, its resonance is not eliminated but moved up and can be close or equal to the resonance created by one of the other adjacent strips. To overcome this problem a second ideal ON/OFF switch is inserted as shown in Fig. 9a. In Fig. 9b, ideal ON/OFF diode switches are inserted instead of the gaps to end with an electronically controlled FSS resonant frequencies.

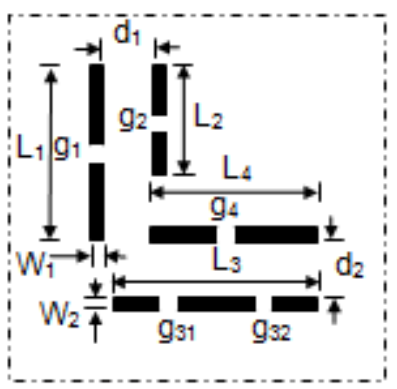

(a)

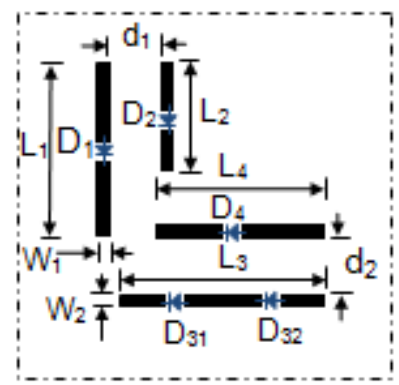

(b)

Fig. 9. The parallel metallic strips FSS: (a) With gaps (b) With diode switches.

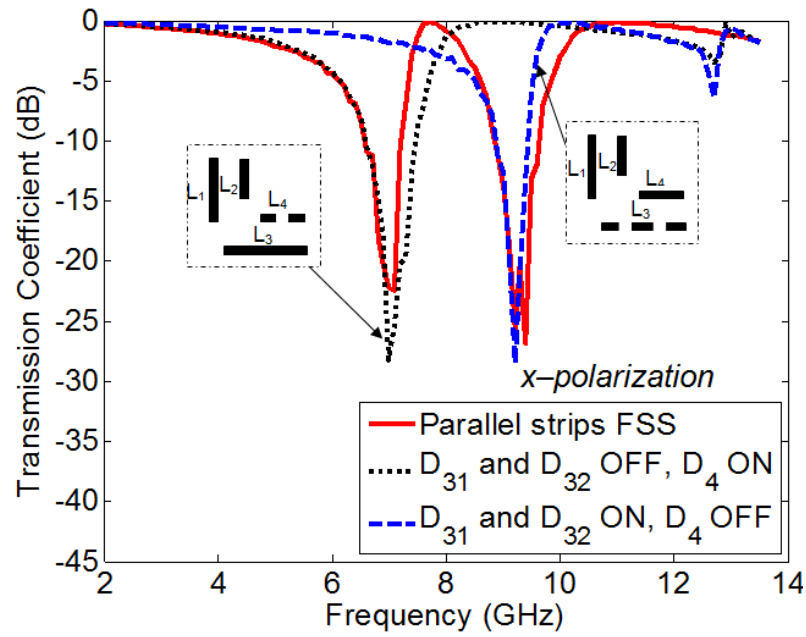

(a)

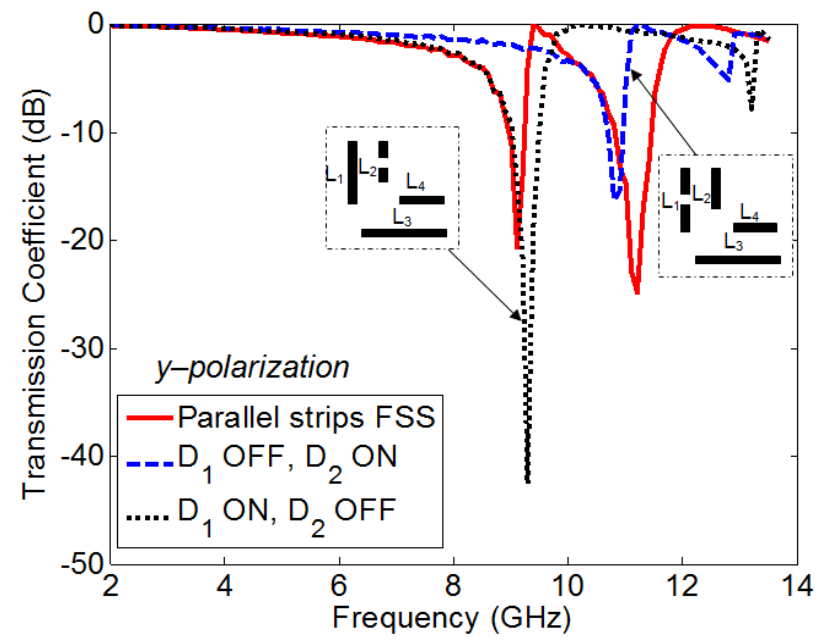

(b)

Fig. 10. Simulated transmission coefficient for the : (a) $x$ polarization - (b) $y$ polarization.

received 10 Mar 2018; for review 23 Mar 2018; accepted 26 Sep 2018 (c) 2018 SBMO/SBMag
(c))BY

ISSN 2179-1074 
Figs. 11.a and 11.b show the transmission coefficient of the FSS of Fig. 9 for different switches states using WCIP method and simulation. When the switches $D_{31}$ and $D_{32}$ are both OFF, the only resonance present concerns the strip of length $L_{4}$. If $D_{32}$ is ON and $D_{31}$ is maintained OFF, two resonant frequencies are shown where the lowest is recorded at about $9 \mathrm{GHz}$ and it concerns the strip of length $L_{4}$ and the highest resonant frequency observed at about $10.1 \mathrm{GHz}$ concerns the strip of length $8 \mathrm{~mm}$ extracted from the strip $L_{3}$ by decrementing its length with $5.684 \mathrm{~mm}$. In the case where the $D_{31}$ is $\mathrm{ON}$ and $D_{32}$ is OFF, an improvement of $98.44 \%$ of the bandwidth centered at $9.2 \mathrm{GHz}$ is obtained as compared to the structure of Fig. 2. It is due to the creation of new near $L_{4}$ resonance by the second strip constituting $L_{3}$ strip of length $9.684 \mathrm{~mm}$.

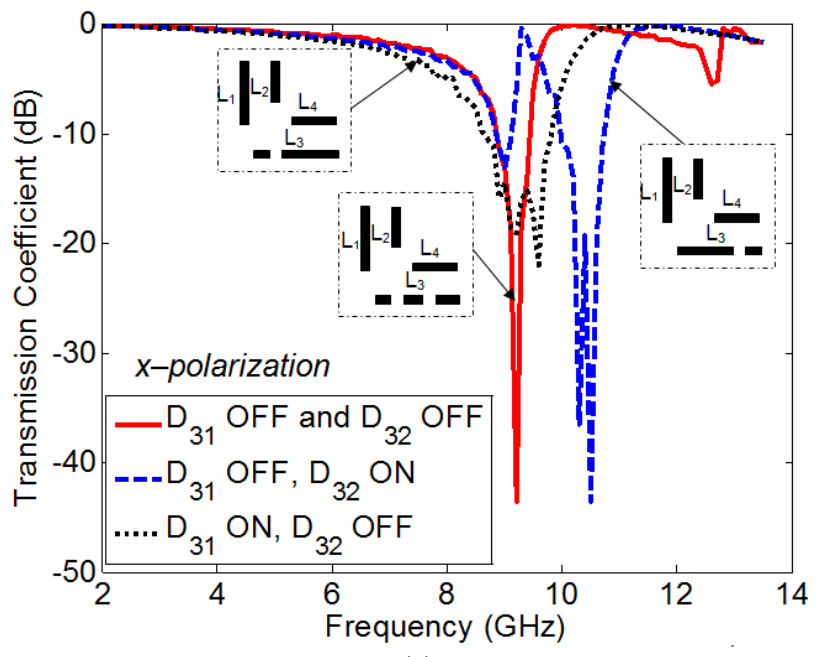

(a)

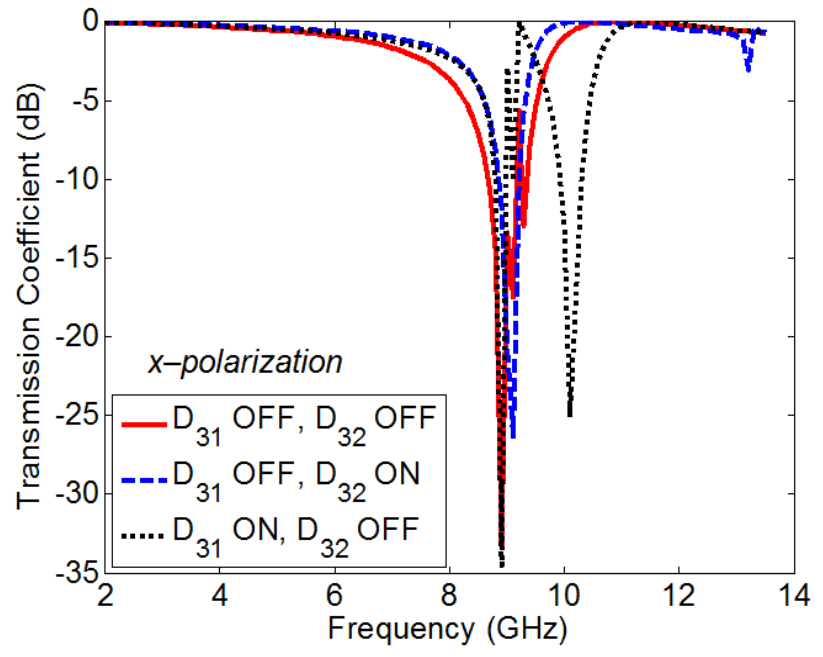

(b)

Fig. 11. Simulated transmission coefficient for the $x$ polarized FSS : (a) WCIP results - (b) Simulated results.

To add a third resonance in the $x$ polarization, a horizontal strip is added as shown in Fig. 12.

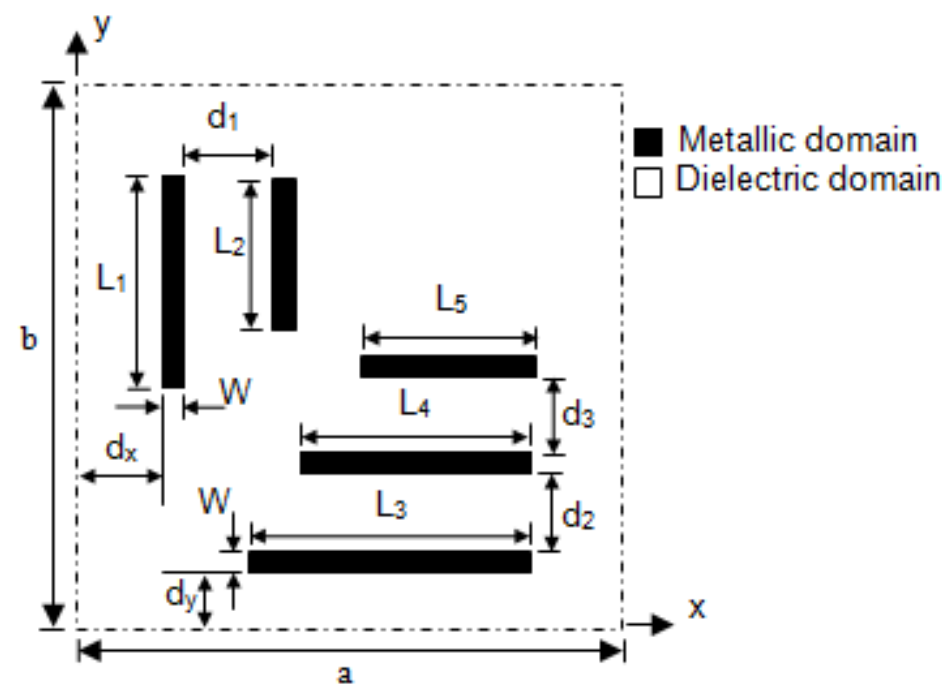

Fig. 12. Parallel metallic strips FSS with three horizontal strips.

Brazilian Microwave and Optoelectronics Society-SBMO Brazilian Society of Electromagnetism-SBMag received 10 Mar 2018; for review 23 Mar 2018; accepted 26 Sep 2018 (c) 2018 SBMO/SBMag (cc) BY

ISSN 2179-1074 
The structure of Fig. 12 has the following dimensions: $a=b=20 \mathrm{~mm}, L_{1}=11.81 \mathrm{~mm}, L_{2}=7.868 \mathrm{~mm}$, $L_{3}=13.5081 \mathrm{~mm}, L_{4}=10.868 \mathrm{~mm}, L_{5}=7.868 \mathrm{~mm}, W=0.983 \mathrm{~mm}$ and $d_{1}=1.983 \mathrm{~mm}, d_{2}=d_{3}=2.752 \mathrm{~mm}$, $d_{\mathrm{x}}=d_{\mathrm{y}}=1.2 \mathrm{~mm}$.

In the $x$ polarization three resonant frequencies are observed at about $7 \mathrm{GHz}, 8.6 \mathrm{GHz}$ and $11 \mathrm{GHz}$ as shown in Fig. 13.a. In the $y$ polarization two resonant frequencies of about $7.9 \mathrm{GHz}$ and $10.6 \mathrm{GHz}$ are observed as represented by Fig. 13.b. In addition to the results obtained by the WCIP method, simulated results are also plotted on Figs. 13.a and 13.b, and a good agreement is reported.

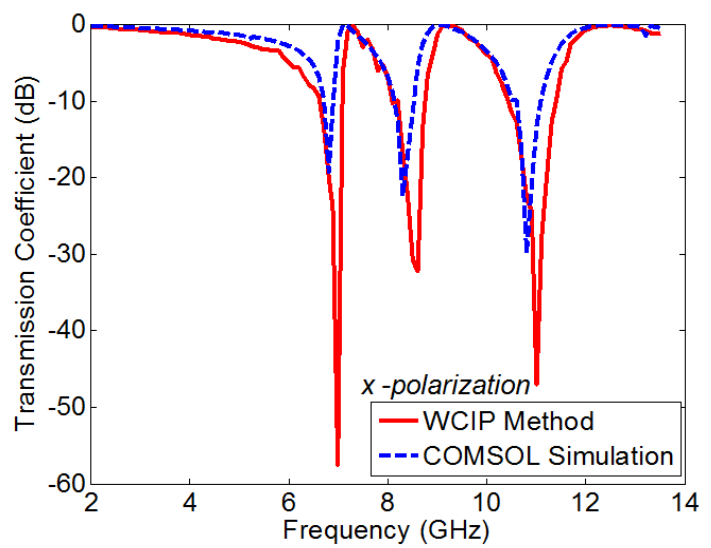

(a)

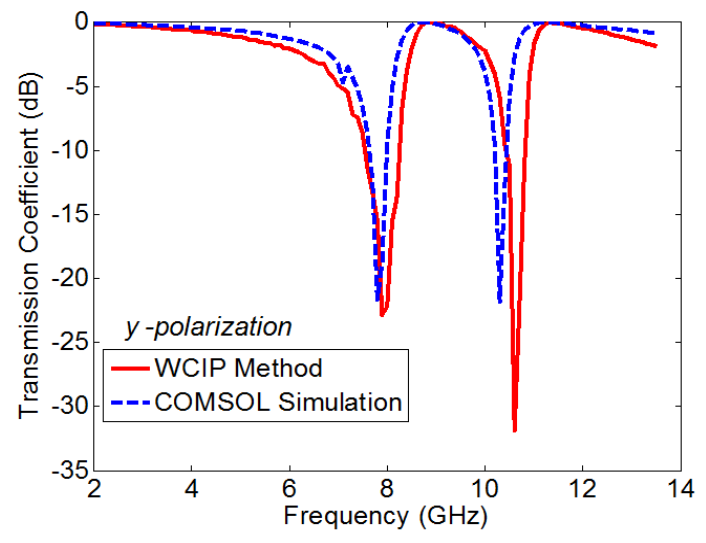

(b)

Fig. 13. Simulated transmission coefficient for the: (a) $x$ polarization - (b) $y$ polarization.

To save a space and get three resonant frequencies in both directions of polarization a rectangular ring is added in the structure of Fig. 2. Fig. 14 shows the designed and fabricated novel structure where the geometrical dimensions of the proposed FSS unit cell are: $a=b=20 \mathrm{~mm}, L_{1}=10.81 \mathrm{~mm}$, $L_{2}=L_{4}=7.868 \mathrm{~mm}, \quad L_{3}=9.5081, W=0.983 \mathrm{~mm}, \quad$ and $d_{1}=d_{2}=0.983 \mathrm{~mm}, \quad W_{\mathrm{a}}=L_{\mathrm{a}}=11.8 \mathrm{~mm}, d_{3}=5.9 \mathrm{~mm}$, $d_{x}=d_{y}=1.2 \mathrm{~mm}$.

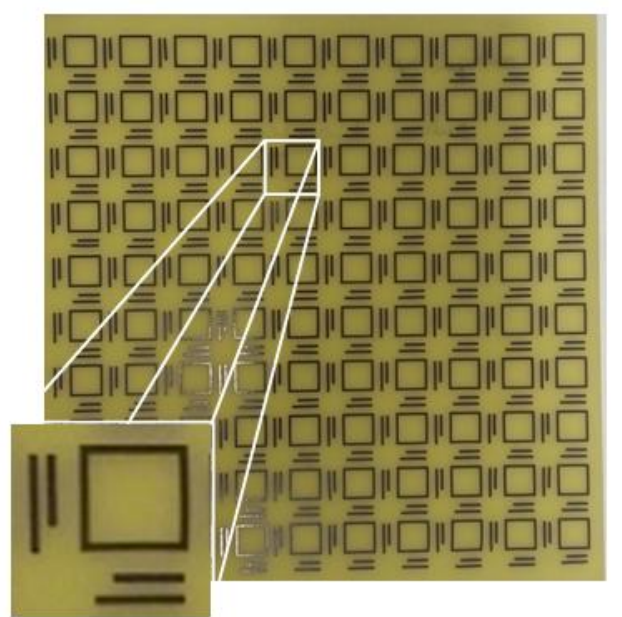

(a)

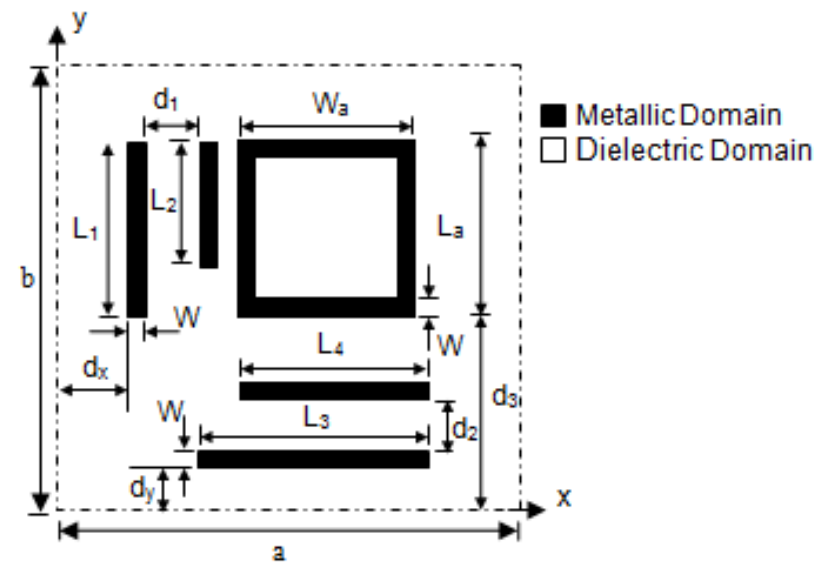

(b)

Fig. 14. FSS ring structure with parallel metallic strips: (a) Realized FSS with an array of $\mathbf{1 0} \times \mathbf{1 0}$ unit cells and - (b) FSS unit cell geometry.

received 10 Mar 2018; for review 23 Mar 2018; accepted 26 Sep 2018 (C) 2018 SBMO/SBMag (c)) BY

ISSN 2179-1074 
The FSS unit cell of Fig. $14 \mathrm{~b}$ is described by $200 \times 200$ pixels and the iterative process is stopped after 350 iterations.

The WCIP results are validated by comparing them to the simulated results and the experimental results, a good agreement is observed.

The transmission coefficients $S_{12}$ of the structure when it is excited by an $x$ and $y$ polarized normal plane waves are shown in Figs. 15.a and 15.b respectively.

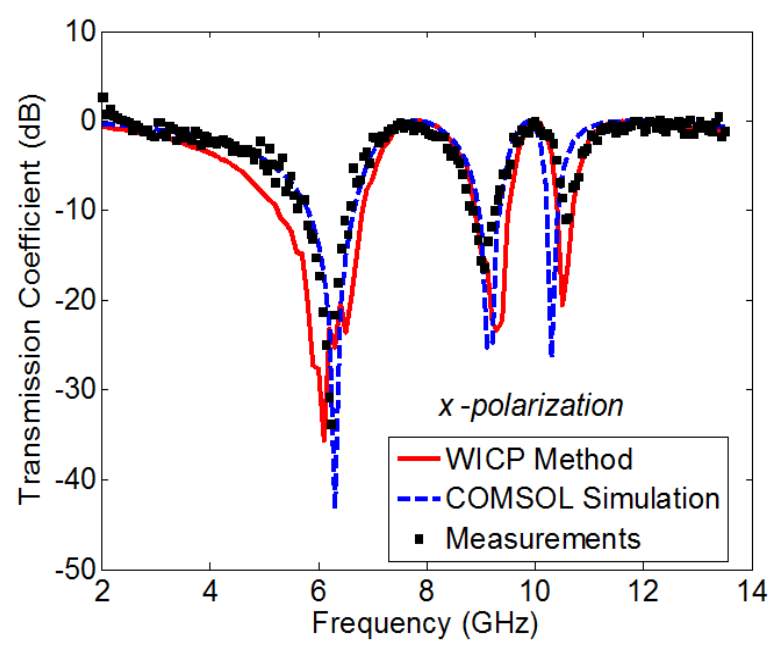

(a)

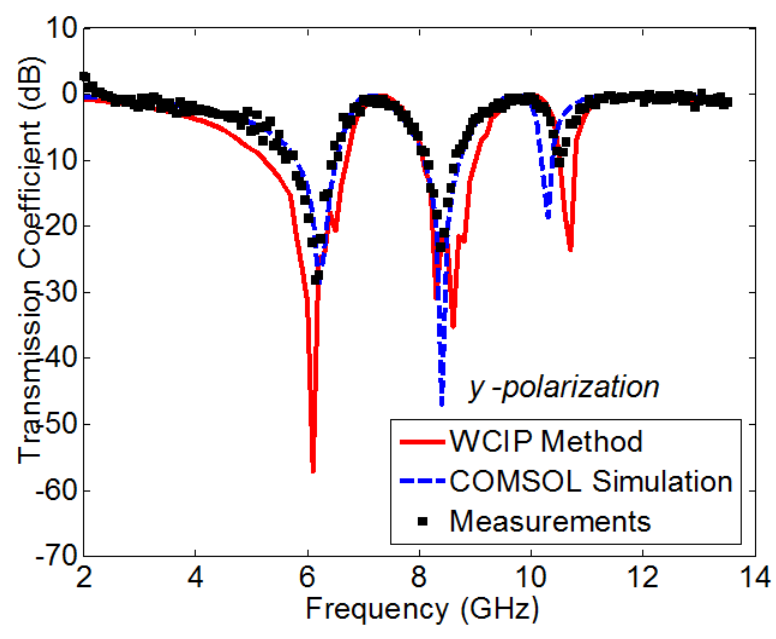

(b)

Fig. 15. Simulated and measured transmission coefficient for the: (a) $x$ polarization - (b) $y$ polarization.

As shown in Fig. 15 the structure presents three resonant frequencies at about $6.1 \mathrm{GHz}, 9.3 \mathrm{GHz}$ and $10.5 \mathrm{GH}$ with bandwidths of $1.554 \mathrm{GHz}, 0.632 \mathrm{GHz}$ and $28.1 \mathrm{MHz}$ at $-10 \mathrm{~dB}$ respectively when it is excited with an $x$ polarized plane wave, and three resonant frequencies at about $6.1 \mathrm{GHz}, 8.3 \mathrm{GHz}$ and $10.7 \mathrm{GHz}$ with bandwidths of $1.446 \mathrm{GHz}, 0.93 \mathrm{GHz}$ and $27.6 \mathrm{MHz}$ respectively when the structure is excited with a $y$ polarized plane wave. In addition to the results obtained by the WCIP method, simulated results are also plotted on Figs. 15.a. and 15.b, and a good agreement is reported.

\section{FSS SYNTHESIS BASED ON NON COUPLED PARALLEL METALLIC STRIPS AND A RING}

A multiband FSS with dual polarization can be synthesized only by giving the corresponding strips lengths and their number being equal to the number of the desired resonant frequencies in the two polarizations.

The structure that can be fabricated in the laboratory is an array of 10x10 cells with cell dimensions $a=b=20 \mathrm{~mm}$, a substrate thickness of $1 \mathrm{~mm}$ and a relative dielectric constant of 4.4 .

An FSS with an adjusted resonant frequency can be also obtained from rectangular metallic ring length's variation since its resonance occurs when the operating wavelength is equal to the circumference of the ring. The outlines of the procedure of FSS synthesis based on metallic strips and a ring are summarized in the flowchart given in Fig. 16. 


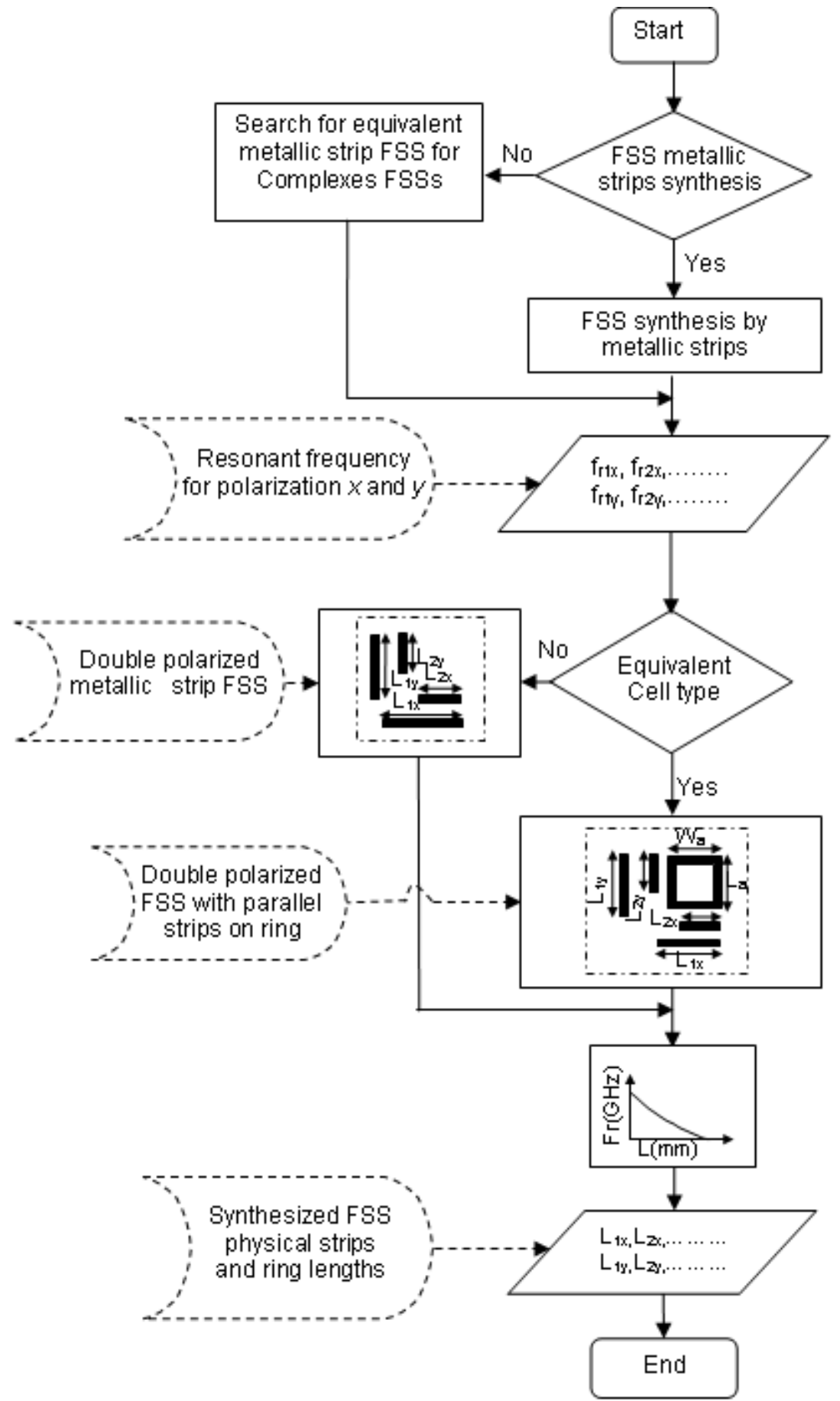

Fig. 16. Strips length and ring circumference determination procedure outlines.

\section{A. Metallic strip/ring length determination for a desired resonant frequency}

The configuration of the metallic strip unit cell and metallic ring unit cell are presented in Figs. 17.a and 17.b respectively. In the case of a metallic strip FSS unit cell of Fig. 17.a, the geometrical dimensions are: $a=b=20 \mathrm{~mm}$, a strip width $W=0.789 \mathrm{~mm}$ and the strip length $L$ is ranging from $6 \mathrm{~mm}$ to $19 \mathrm{~mm}$ with an increment of $1 \mathrm{~mm}$. For the metallic ring FSS geometry of Fig. 17.b having the same unit cell dimensions $a=b=20 \mathrm{~mm}$, a strip width $W_{r}=0.983 \mathrm{~mm}$ and a ring width $W_{a}=12 \mathrm{~mm}$ but the ring 
length $L_{\mathrm{a}}$ varies from $5 \mathrm{~mm}$ to $16 \mathrm{~mm}$. The FSS structures substrate have a $1 \mathrm{~mm}$ thickness and a 4.4 dielectric constant. They are excited with an $x$-polarized normal incident plane wave.

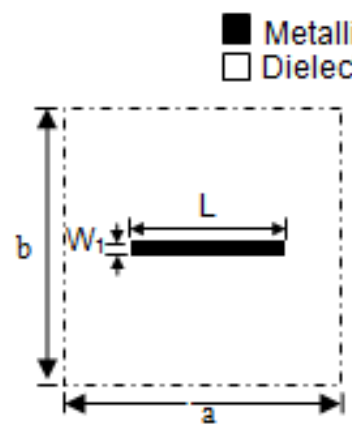

(a)

Metallic Domain

ielectric Domain

Fig. 17. FSS unit cell geometry : (a) Metallic strip - (b) Metallic ring.

The presented approach is summarized in the flowchart shown in Fig. 18. First of all, the type of FSS is to be chosen between an FSS made of only parallel metallic strips and an FSS made of parallel metallic strips and a ring. Once the FSS type is chosen, the desired resonant frequencies are inserted once a time in Fig. 19 and the corresponding curve either the strip curve or the ring curve is used to extract the strips length and/or the ring length $L_{\mathrm{a}}$ representing the remaining dimension to be determined in order to end with an FSS with the desired frequency response.

Using the WCIP method and the simulator, the resonant frequency of the FSS structures of Fig. 17 is calculated for different values of $L$ and $L_{\mathrm{a}}$ and shown in Fig. 18 in which the interpolation (solid and dashed lines) is insured by the use of the least mean square method. At this stage, FSS with one resonant frequency ranging from $4.5 \mathrm{GHz}$ to $12.25 \mathrm{GHz}$ can be realized by only using one metallic strip. For more resonances additional metallic strips corresponding to the desired resonant frequencies are inserted and arranged as presented in Fig. 2 since it was shown that no coupling exist between the metallic strips under this arrangement.

Figure 18 presents a flowchart summarizing the different steps of obtaining the resonant frequency $f_{r}$ as a function of the strip's length $L$ and as a function of a ring length $L_{\mathrm{a}}$. In Fig. 19, the obtained characteristic plot relating the desired resonant frequency to the strip's length $L$ or the ring's length $L_{\mathrm{a}}$ is shown. The obtained characteristic plot limits the synthesized FSS resonant frequencies to range from $4.8 \mathrm{GHZ}$ to $12 \mathrm{GHz}$ however the synthesized metallic ring FSS resonant frequencies are restricted to the interval varying from $5 \mathrm{GHZ}$ to $8 \mathrm{GHz}$. 


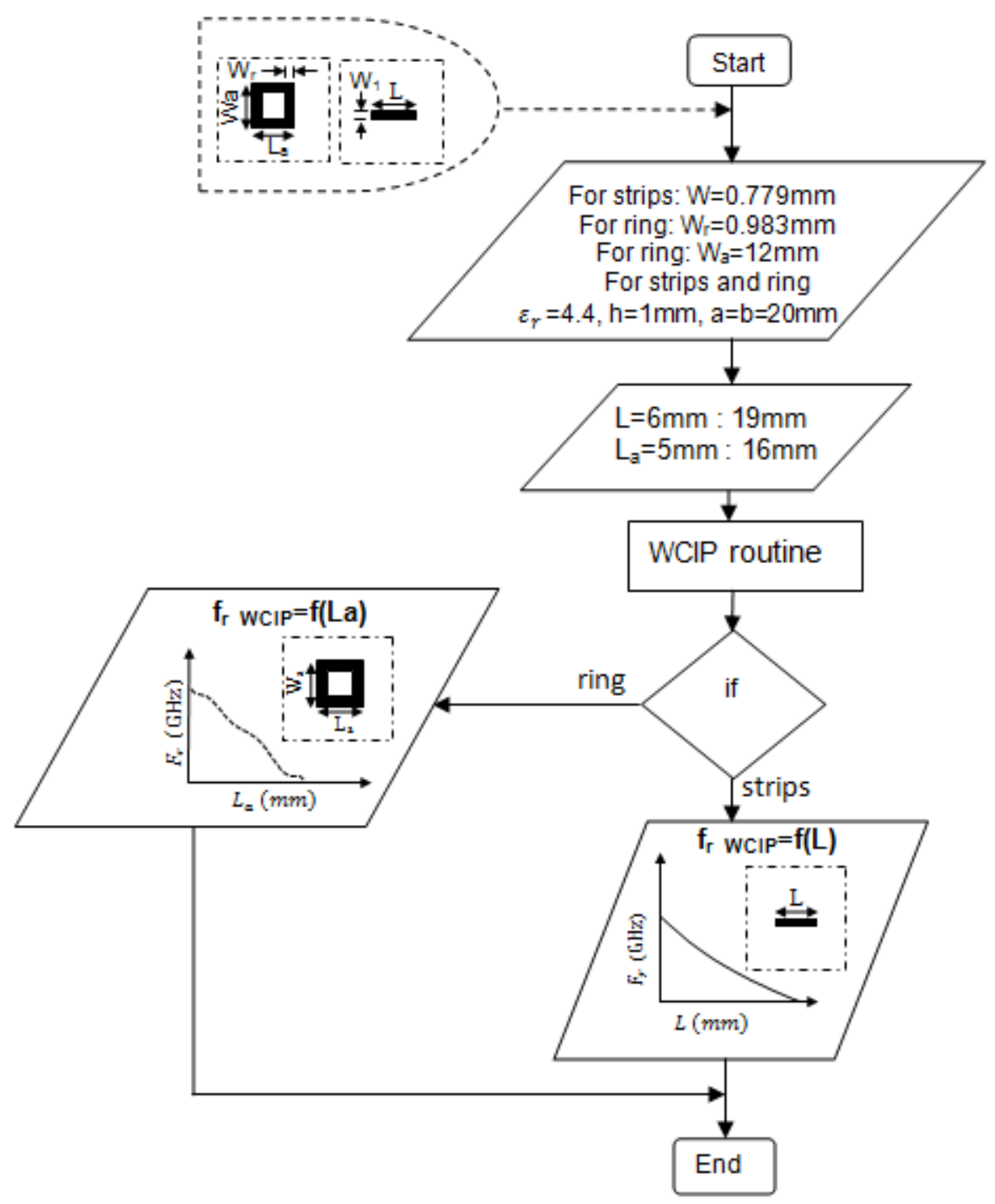

Fig. 18. Flowchart summarizing the different steps for obtaining the $f_{r}$ as a function of the strip length $L$ or the ring length $L_{\mathrm{a}}$. 


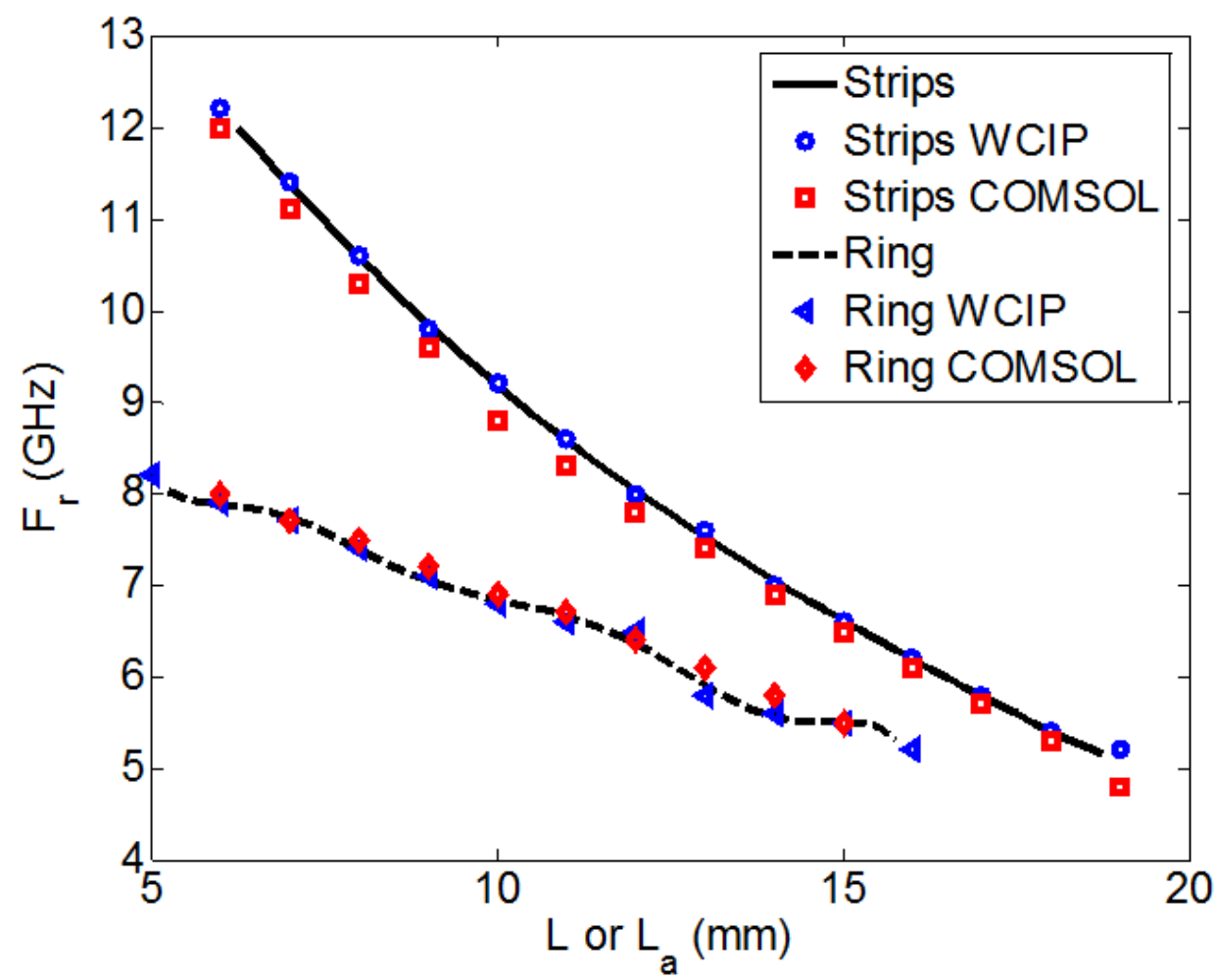

Fig. 19. Resonance frequency as a function of the metallic strip length.

\section{B. Approach validation}

To validate the proposed approach, the measured results shown in Figs. 3.a and 3.b, 15.a and 15.b and concerning respectively the dual polarized parallel metallic strip FSS of Fig. 2 and the dual polarized FSS with parallel metallic strips and a ring of Fig. 14 are taken as references.

Dual polarized parallel metallic strips FSS: Tables II and III show the values of the metallic strip length $L_{\mathrm{i}}$ obtained from Fig. 19 and necessary to realize the measured resonant frequencies of Figs. 3.a and 3.b respectively. The transmission power of the present approach dual polarized parallel metallic strips FSS calculated by the WCIP method are shown in Figs. 20.a and 20.b for both source polarizations $x$ and $y$ respectively.

TABLE II. ERROR IN THE PRESENT APPROACH RESONANT FREQUENCY AS COMPARED TO THE MEASURED RESONANT FREQUENCY FOR AN $X$ POLARIZED SOURCE EXCITING THE DUAL POLARIZED PARALLEL METALLIC STRIPS FSS

\begin{tabular}{ccc}
\hline \multicolumn{3}{c}{ Polarization $\boldsymbol{x}$} \\
\hline $\boldsymbol{f}_{\boldsymbol{r} \text { (measured) }}$ & $\boldsymbol{f}_{\boldsymbol{r} \mathbf{1}}$ & $\boldsymbol{f}_{\boldsymbol{r} \mathbf{2}}$ \\
\hline$L_{i}$ & $\mathbf{6 . 9 4 5}$ & $\mathbf{9 . 2 4 5}$ \\
$f_{r_{-} \text {WCIP }}(\mathrm{GHz})$ & 6.154 & 9.902 \\
$f_{r}$ Eq. (10) & 9.12 & 9.1 \\
Error \% WCIP & 0.64 & 13.037 \\
Error \% Eq. (10) & 31.32 & 1.56 \\
\hline
\end{tabular}


TABLE III. ERROR IN THE PRESENT APPROACH RESONANT FREQUENCY AS COMPARED TO THE MEASURED RESONANT FREQUENCY FOR A $Y$ POLARIZED SOURCE EXCITING A DUAL POLARIZED PARALLEL METALLIC STRIPS FSS

\begin{tabular}{|c|c|c|}
\hline \multicolumn{3}{|c|}{ Polarization $y$} \\
\hline & $f_{r 1}$ & $f_{r 2}$ \\
\hline$f_{r \text { (measured) }}$ & 8.9 & 11.03 \\
\hline$L_{i}$ & 10.48 & 7.42 \\
\hline$f_{r_{-} \text {WCIP }}(\mathrm{GHz})$ & 8.6 & 11.3 \\
\hline$f_{r}$ Eq. (10) & 12.953 & 18.145 \\
\hline Error \% WCIP & 3.37 & 2.44 \\
\hline Error \% Eq. (10) & 45.54 & 64.51 \\
\hline
\end{tabular}

The recorded error in the resonant frequency obtained by the proposed approach as compared to measurement varies from $0.64 \%$ to $3.37 \%$ whereas the error produced using equations (10) and (11) reaches $64.51 \%$.

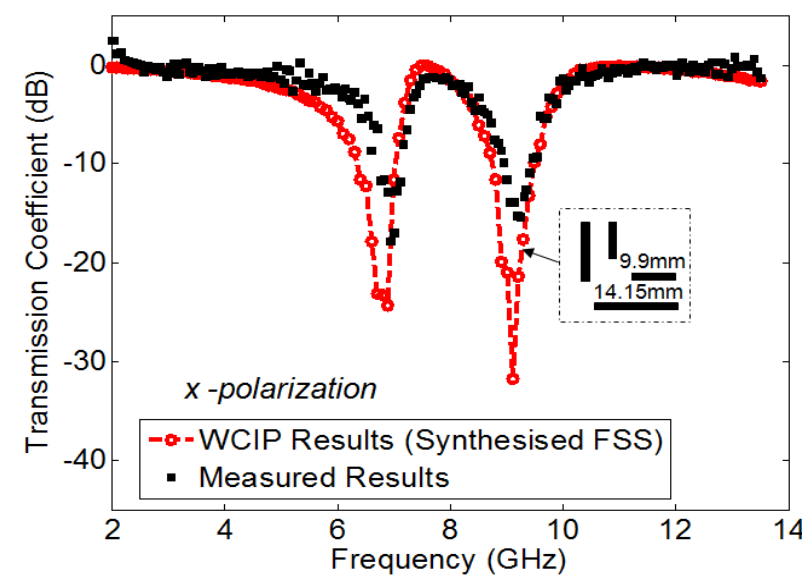

(a)

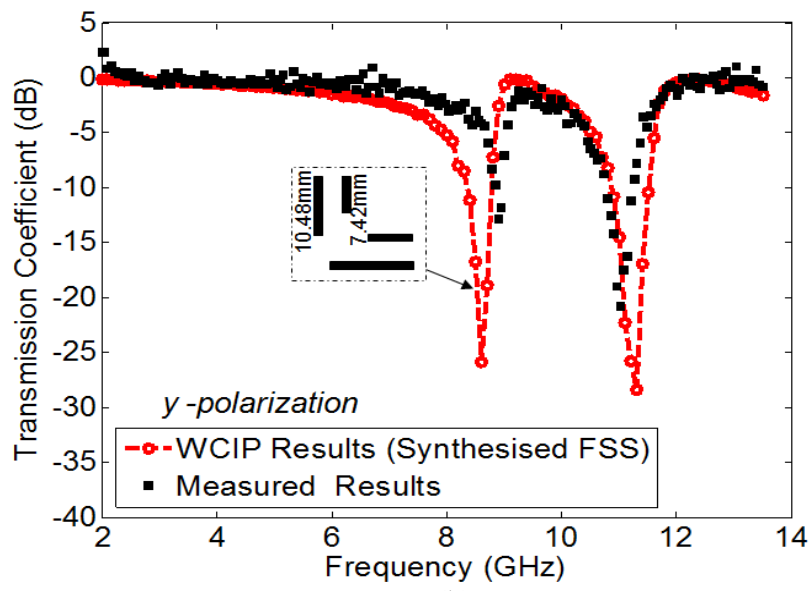

(b)

Fig. 20. Transmission Coefficient of the dual polarized parallel metallic strips FSS the equivalent metallic structure for the: (a) $x$ polarization - (b) $y$ polarization.

Dual polarized FSS with parallel metallic strips and a ring: Table IV and Table V show the ring and strip lengths $L_{\mathrm{a}}, L_{1}, L_{2}$ represented by $L_{\mathrm{i}}$ values and corresponding to the measured resonant frequencies of $6 \mathrm{GHz}, 9.073 \mathrm{GHz}$ and $10.57 \mathrm{GHz}$ respectively. The measured resonant frequencies concern the dual polarized metallic ring and parallel strips FSS shown in Fig. 14 and for which the measurements are presented in Figs. 15.a and 15.b for $x$-polarized and $y$-polarized sources respectively and exciting the FSS of Fig. 14. The transmission power of the present approach dual polarized FSS with parallel metallic strips and a ring calculated by the WCIP method are shown in Figs. 21.a and 21.b for both source polarizations $x$ and $y$ respectively. 
Journal of Microwaves, Optoelectronics and Electromagnetic Applications, Vol. 17, No. 4, December 2018 DOI: http://dx.doi.org/10.1590/2179-10742018v17i41264

TABLE IV. ERROR IN THE PRESENT APPROACH RESONANT FREQUENCY AS COMPARED TO THE MEASURED RESONANT FREQUENCY FOR AN X POLARIZED SOURCE EXCITING THE DUAL POLARIZED FSS WITH PARALLEL METALLIC STRIP AND A RING

\begin{tabular}{cccc}
\hline & Polarization $\boldsymbol{x}$ & & \\
\hline & $\boldsymbol{f}_{\mathbf{r} 1}$ & $\boldsymbol{f}_{\mathbf{r} 2}$ & $\boldsymbol{f}_{\mathbf{r 3}}$ \\
\hline $\boldsymbol{f}_{\boldsymbol{r} \text { (measured) }}$ & $\mathbf{6 . 2 5 5}$ & $\mathbf{9 . 0 7 3}$ & $\mathbf{1 0 . 5 7}$ \\
\hline$L_{\mathrm{i}}$ & 12.105 & 10.143 & 8.04 \\
$f_{r_{-} \text {WCIP }}(\mathrm{GHz})$ & 6 & 8.8 & 10.4 \\
$f_{r}$ Eq. $(10)$ & 10.665 & 12.727 & 16.039 \\
Error \% WCIP & 3.61 & 3.01 & 1.61 \\
Error \% Eq. (10) & 70.50 & 40.27 & 51.74 \\
\hline
\end{tabular}

TABLE V. ERROR IN THE PRESENT APPROACH RESONANT FREQUENCY AS COMPARED TO THE MEASURED RESONANT FREQUENCY FOR A Y POLARIZED SOURCE EXCITING THE DUAL POLARIZED FSS WITH PARALLEL METALLIC STRIP AND A RING

\begin{tabular}{cccc}
\hline \multicolumn{4}{c}{ Polarization $\boldsymbol{y}$} \\
\hline & $\boldsymbol{f}_{\mathbf{r} 1}$ & $\boldsymbol{f}_{\mathbf{r} 2}$ & $\boldsymbol{f}_{\mathbf{r} 3}$ \\
\cline { 2 - 4 } $\boldsymbol{f}_{\boldsymbol{r} \text { (measured) }}$ & $\mathbf{6 . 1 4}$ & $\mathbf{8 . 3 8 3}$ & $\mathbf{1 0 . 5 1}$ \\
\hline$L_{\mathrm{i}}$ & 12.51 & 11.28 & 8.12 \\
$f_{r_{-} \text {WCIP }}(\mathrm{GHz})$ & 6 & 8.2 & 10.4 \\
$f_{r}$ Eq. $(10)$ & 10.32 & 11.444 & 15.884 \\
Error \% WCIP & 2.2800 & 2.1800 & 1.0500 \\
Error \% Eq. $(10)$ & 68.08 & 36.51 & 51.31 \\
\hline
\end{tabular}

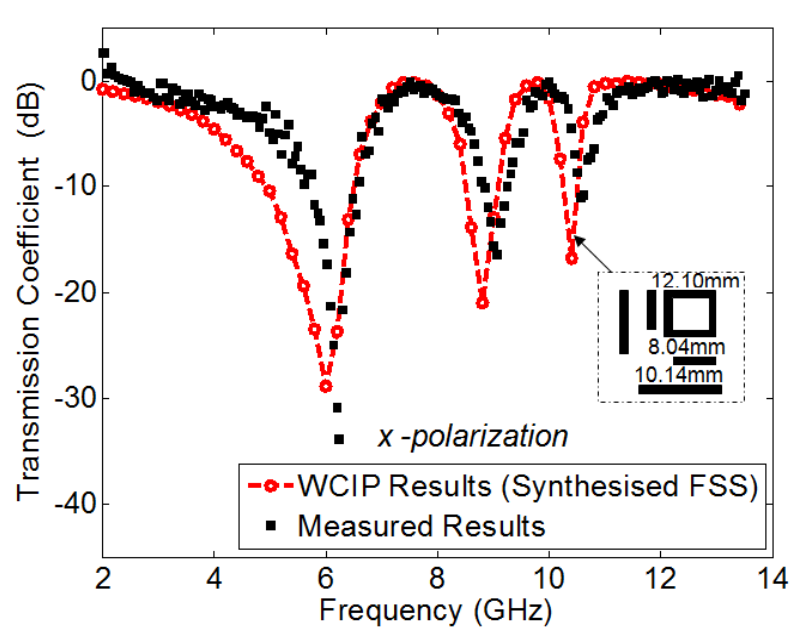

(a)

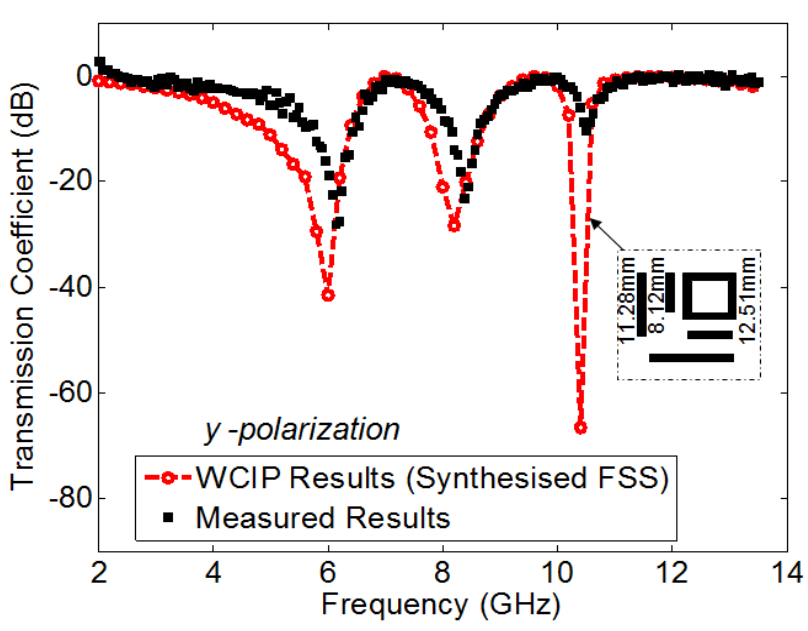

(b)

Fig. 21. Transmission coefficient of the dual polarized FSS with metallic parallel strips and a ring for the: (a) $x$ polarization (b) $y$ polarization.

As shown in Tables IV and $\mathrm{V}$ the error in the resonant frequencies calculated by the proposed approach remains less than $3.61 \%$ however the error percent of the resonant frequencies calculated by equations (10) and (11) varies between $36.51 \%$ and $70.50 \%$.

The presented synthesis approach anticipates more precisely the resonant frequency of the metallic strip/ring FSS. Using Fig. 19 to extract pairs of resonant frequencies and strip/ring lengths $\left(f_{\mathrm{r}}, L_{\mathrm{i}}\right)$ then inserting them a pair at a time in equation (12) obtained from equation (10), a curve relating the 
relative effective dielectric constant $\epsilon_{r_{-} e f f}$ of the FSS and the resonant frequencies or the strip/ring length are obtained and shown in Fig. 22. As a result equation (10) and the resulting curves also provide errors in the strip/ring FSS resonant frequencies determination less than $4.25 \%$ and errors in the strip/ring length of also less than $4.25 \%$ as shown in Figs. 23 and 24 respectively since they are issued from the same synthesis and analysis approaches.

$$
\varepsilon_{\mathrm{r}_{-} \mathrm{eff}}=\frac{\mathrm{c}^{2}}{4 \mathrm{~L}_{\mathrm{i}}^{2} \mathrm{f}_{\mathrm{r}}^{2}}
$$

The difference between the experiment results and the simulated results are probably due to the non exact value of the substrate dielectric constant of the manufactured FSS since its is provided by the constructor and not extracted from experiment before measuring the manufactured FSS. A part of this difference may be related to the use of a limited number of TE and TM modes arising from the limited number of pixels describing the FSS interface. In addition the iterative procedure of the WCIP method is stopped at a limited number of iterations presenting initially an accepted error in the determination of the reflection and transmission coefficients.

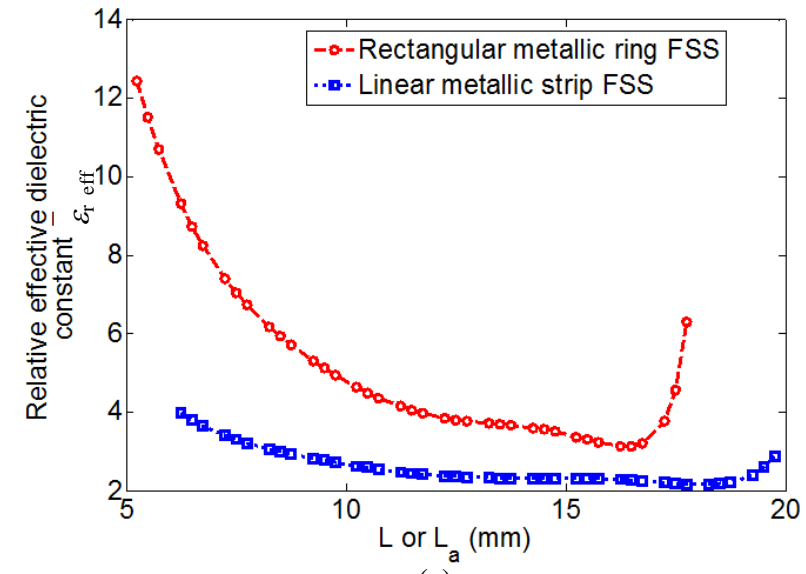

(a)

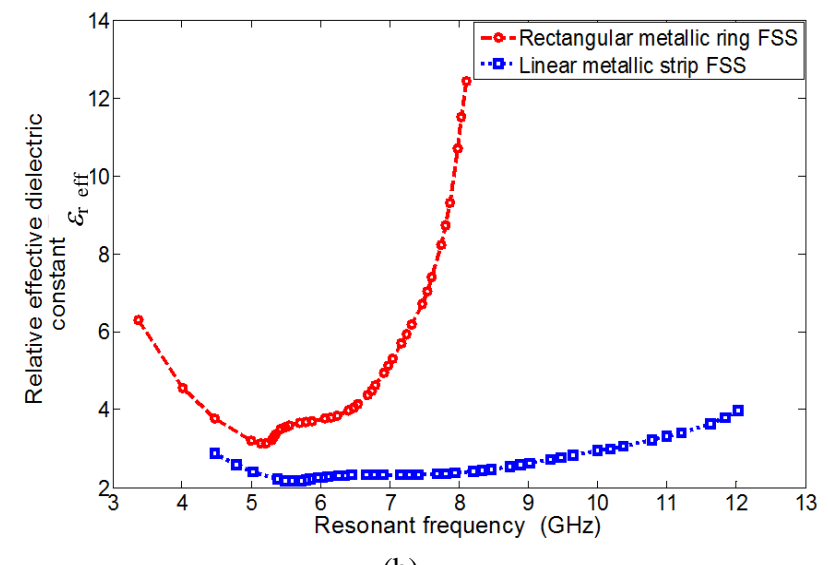

(b)

Fig. 22. Effective dielectric constant as a function of the: (a) Metallic FSS metallic strip/ring length (b) Resonant frequency of the strip/ring FSS

\section{Approach error estimation}

The synthesis approach error in the FSS's strip/ring length as a function of the desired resonant frequency of the metallic strip/ring FSS is shown in Fig. 23 where a maximum error of $4.25 \%$ in the strip length is recorded for a desired resonant frequency of 9.18GHz. Fig. 24 presents the analysis approach error in the resonant frequency of the metallic strip/ring FSS as a function of a given FSS's strip/ring length where the maximum error of $4.25 \%$ is observed for the strip FSS of $10 \mathrm{~mm}$ length. The errors are identical since a metallic strip FSS of $10 \mathrm{~mm}$ length resonates at $9.2 \mathrm{GHz}$. When comparing the least square method results to those of the WCIP method the error is lower since the WCIP method results are used as the 
basis data to obtain the least square method curve. Comparing the simulation curve to the least square curve, a higher error value is recorded in the majority part of the frequency/length range since there is an initial error between the WCIP results and the simulation results as it can be seen in Figs 3, 13 and 15 due to the limited number of modes used as a modal basis in the WCIP method. Moreover also the limited number of iterations imposing an acceptable error after the iterative process convergence represents an additional source of error.

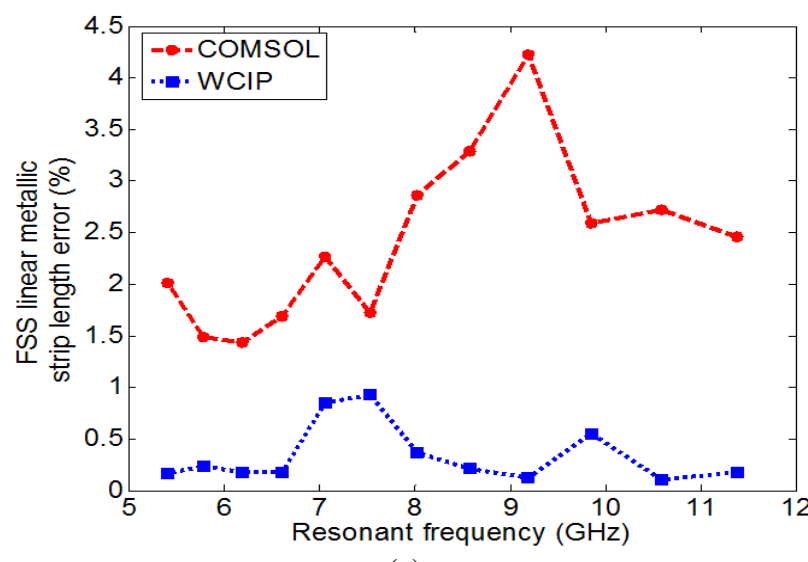

(a)

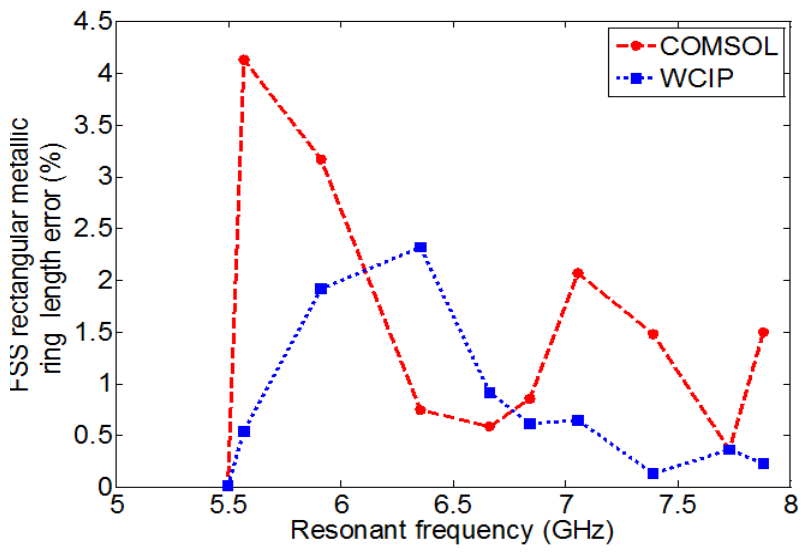

(b)

Fig. 23. Strip/ring length error versus the desired resonant frequency for:

(b) Metallic strip FSS (c) Metallic ring FSS

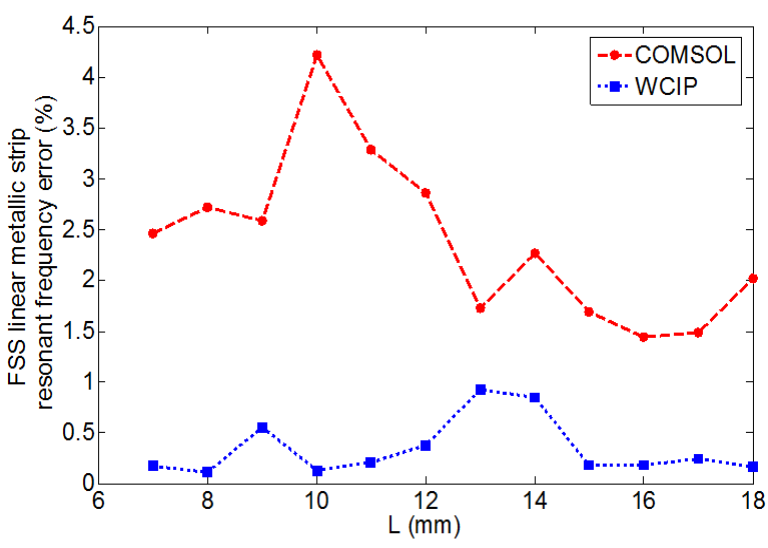

(a)

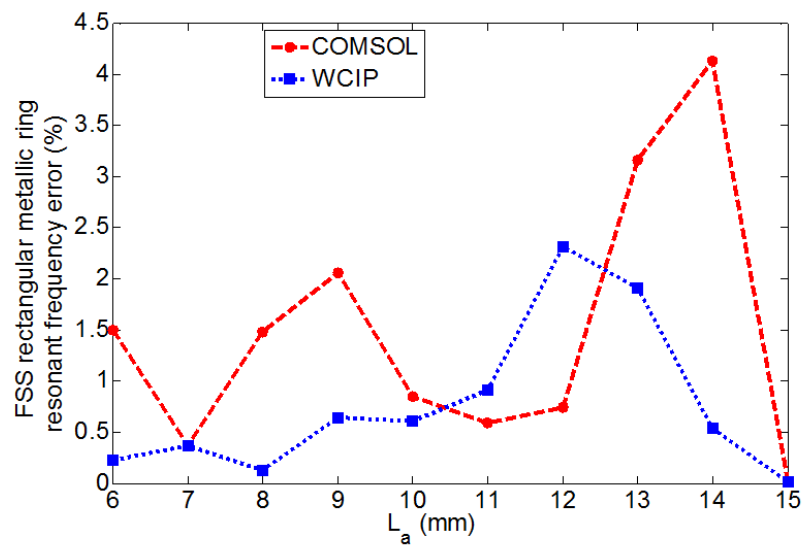

(b)

Fig. 24. Strip/ring resonant frequency error versus given strip/ring lengths for: (b) Metallic strip FSS (c) Metallic ring FSS 
Journal of Microwaves, Optoelectronics and Electromagnetic Applications, Vol. 17, No. 4, December 2018 DOI: $\underline{\text { http://dx.doi.org/10.1590/2179-10742018v17i41264 }}$

\section{EQUIVALENT STRUCTURE OF AN OPEN NOTCHED QUASI-SQUARE METALLIC RING BASED ON METALLIC STRIPS}

The comprehension of the electromagnetic behavior of a structure makes it more useful. Complex structures don't always offer this characteristic. Thus, introducing an approach for obtaining equivalent structures based on non coupled metallic strips is important in such a way that each resonant frequency of the equivalent structure can be easily represented by a simple independent resonant circuit.

In this part the equivalent structure of an open notched quasi-square metallic ring shown in Fig. 25 is determined and it is based on parallel metallic strips. The structure presented in [22] has three resonant frequencies at about $9 \mathrm{GHz}, 11.6 \mathrm{GHz}$ and $12 \mathrm{GHz}$ for an $x$ polarized source and $6.8 \mathrm{GHz}$ in the case of a $y$ polarized source. Using Fig. 19, each resonant frequency gives a value of the physical metallic strip's length that can produce this resonant frequency. By adopting the arrangement shown in Fig. 2.b, the metallic strips are not coupled. Hence each resonant frequency can be independently produced by one metallic strip.

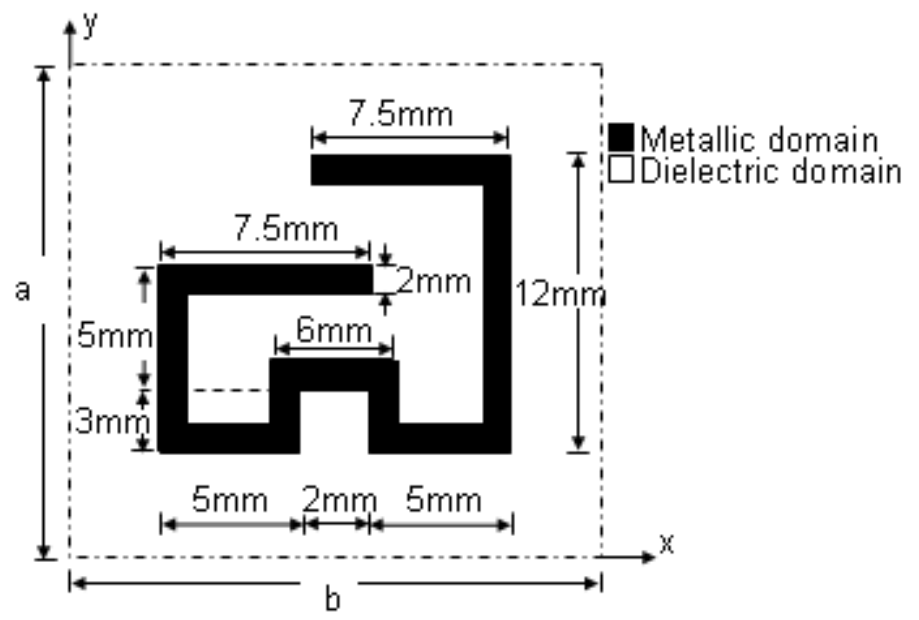

Fig. 25. The open notched quasi-square metallic ring FSS unit cell dimensions [22].

The equivalent FSS based on parallel metallic strips is depicted in Fig. 26. It has three strips in the $x$ directions corresponding to three resonant frequencies when the structure is excited with an $x$ polarized plane wave source, and a single strip in the $y$ direction to produce one resonant frequency when the structure is excited with a $y$ polarized plane wave.

The equivalent structure shown in Fig. 26 has the following dimensions: $a=b=20 \mathrm{~mm}, L_{1}=10.3 \mathrm{~mm}$, $L_{2}=7.4 \mathrm{~mm}, L_{3}=6.7 \mathrm{~mm}, L_{4}=14.9 \mathrm{~mm}, W=2 \mathrm{~mm}, d_{1}=d_{2}=1 \mathrm{~mm}, d_{\mathrm{x}}=d_{\mathrm{y}}=2 \mathrm{~mm}$. 


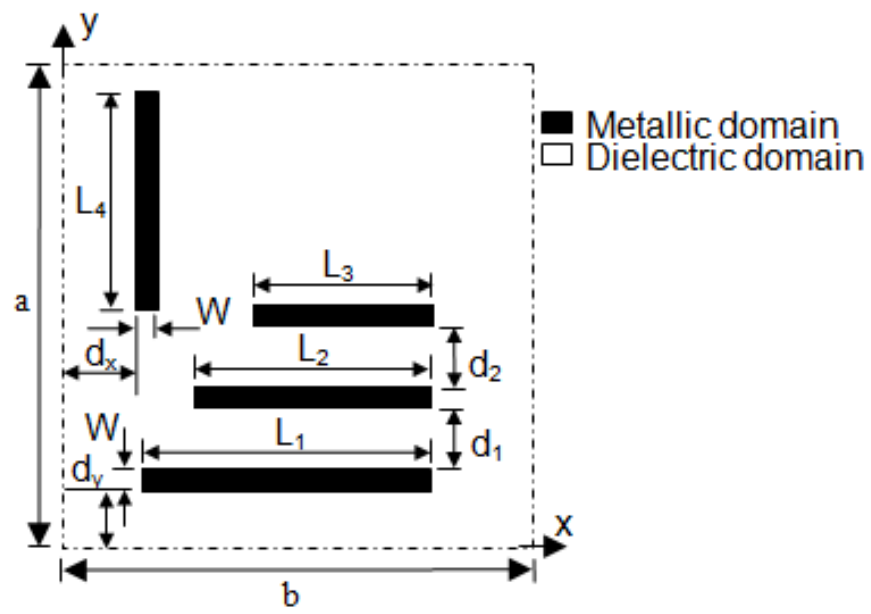

Fig. 26. Unit cell of the equivalent dual polarized FSS based on parallel metallic strips.

Table VI shows the obtained strips lengths using the present approach based on Fig. 19. It provides also the error in the present approach resonant frequency as compared to the measured resonant frequencies of [22] for both $x$ and $y$ polarized sources exciting the equivalent dual polarized FSS based on parallel metallic strips. It does not exceed $2.9 \%$ recorded for the $y$ polarized source.

TABLE VI. EQUIVALENT FSS STRIPS LENGTHS AND RESONANT FREQUENCY ERROR AS COMPARED TO MEASUREMENTS

\begin{tabular}{ccccc}
\hline & \multicolumn{3}{c}{ Polarization $\boldsymbol{x}$} & Polarization $\boldsymbol{y}$ \\
\hline \multirow{2}{*}{$\boldsymbol{f}_{\boldsymbol{r} \text { (measured) }}$} & $\boldsymbol{f}_{\mathbf{r} \mathbf{1}}$ & $\boldsymbol{f}_{\mathbf{r} 2}$ & $\boldsymbol{f}_{\mathbf{r} 3}$ & $\boldsymbol{f}_{\mathbf{r} 1}$ \\
\cline { 2 - 5 } & $\mathbf{9}$ & $\mathbf{1 0 . 8}$ & $\mathbf{1 1 . 6}$ & $\mathbf{6 . 8}$ \\
\hline$L_{\mathrm{i}}$ & 10.3 & 7.4 & 6.7 & 14.9 \\
$f_{r_{-} \text {WCIP }}(\mathrm{GHz})$ & 8.8 & 11 & 11.8 & 6.6 \\
Error \% $(\mathrm{WCIP})$ & 2.22 & 0.9 & 1.7 & 2.9 \\
\hline
\end{tabular}

The transmission power of the open notched quasi-square metallic ring [22] shown in Fig. 25 and its equivalent structure based on metallic strip shown in Fig. 26 for the $x$ and $y$ polarization directions are shown in Fig. 27.

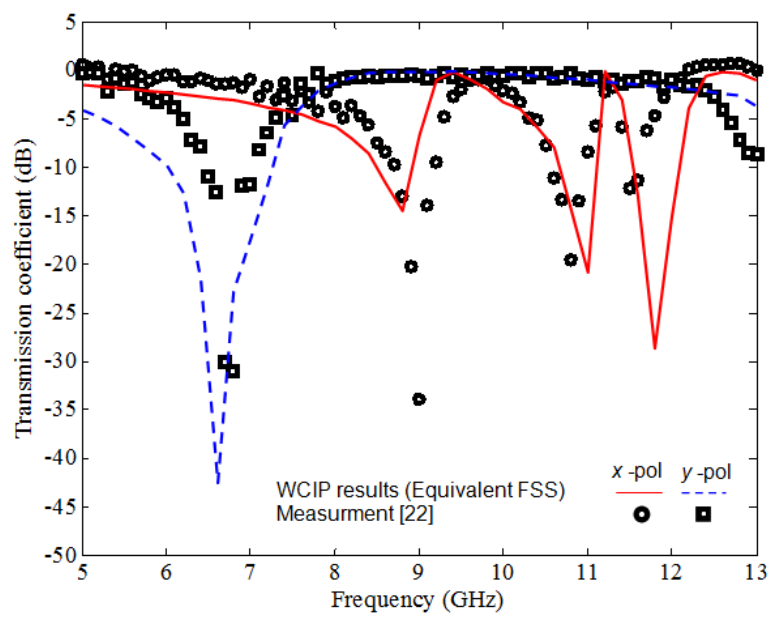

Fig. 27. Transmission power of the equivalent structure for the $x$ and $y$ source polarizations. 


\section{CONCLUSION}

A Dual polarized parallel metallic strips FSS and dual polarized FSS with parallel metallic strips and a ring for multi band applications are proposed. The first proposed structure shows two resonant frequencies at $7 \mathrm{GHz}, 9.4 \mathrm{GHz}$ when the structure is excited with an $x$ polarized plane wave, and two resonant frequencies at $9.1 \mathrm{GHzand} 11.2 \mathrm{GHz}$ for the orthogonal source polarization. The second proposed FSS structure shows three resonant frequencies for the $x$ polarized source at $6.1 \mathrm{GHz}$, $9.3 \mathrm{GHz} 10.5 \mathrm{GHz}$ and three resonant frequencies for the $y$ polarized source at $6.1 \mathrm{GHz} 8.3 \mathrm{GHz}$ 10.7GHz. A resonant frequency can be eliminated when needed by only inserting an ideal ON/OFF switch at the appropriate position along the strip responsible of this resonance. The two structures are manufactured and measured. Good agreement is recorded between WCIP results, simulated results and measurements. Next, an FSS synthesis approach based on non coupled metallic strips and a ring is proposed and validated by measurements of the two manufactured structures. The recorded errors don't exceed $3.61 \%$ when comparing the desired resonant frequencies to the obtained resonant frequencies by analyzing the synthesized FSS. Finally, the proposed FSS synthesis based on parallel metallic strips is used to determine the equivalent structure of an open notched quasi square ring FSS, issued from literature for its complex electromagnetic behavior comprehension. It shows three resonant frequencies for an $x$ polarized source and one resonant frequency for the $y$ polarized source. The obtained equivalent metallic strips FSS resonant frequencies are compared to those of the open notched quasi square ring FSS structure and good agreement is shown with an error remaining less than $2.9 \%$.

\section{REFERENCES}

[1] L. P. S. Antonio, Campos Adaildo, G. d'Assunção, Robson H., C., Maniçoba, Lincoln, M. Araújo, "Software for project and Analysis of Frequency Selective Surfaces," Journal of Microwaves, Optoelectronics and Electromagnetic Applications, Vol. 11No. 1, pp. 56-67, 2012.

[2] S. Bera, S. Bandhu, P.P. Sarkar, "Design of Novel Shaped Compact Frequency Selective Surface with Dual band Applications," International Journal of Electronics \& Communication Technology, Vol. 4, pp. 29-32, 2013.

[3] A. Kaur, G. Er. Saini, Review of Various Designs of Periodic Structures for Frequency Selective Surfaces. International Journal of Engineering Trends and Technology, Vol .4, No. 5, pp. 29-250, 2016.

[4] C. Guo, H. Sun, and X. Lu, "A Novel Dual Band Frequency Selective Surface With Periodic Cell Perturbation," Progress In Electromagnetics Research B, Vol. 9, pp. 137-149, 2008.

[5] T. Mandal, P. S. Pratim, "A Dome Shaped Curved FSS with Extra Wide Band Applications: Design and Theoretical Analysis," Journal of Electronics and Communication Engineering, Vol. 8, No. 1, pp. 53-55, 2013.

[6] Ghaffer. I. Kiani, Kenneth .L. Ford, Karu. P. Esselle, Andrew. R. Weily, C. Panagamuwa, John C. Batchelor, "SingleLayer Bandpass Active Frequency Selective Surface," Microwave and Optical Technology Letters. Vol. 50 No. 8, pp. 2149-2151, August 2008.

[7] Gargi Saha, Chandrakanta Kumar, and Venkataraman V. Srinivasan, "Frequency Selective Surface with Improvised Ring-Resonator for Flexible Design,” Progress In Electromagnetics Research C. Vol. 56, pp. 137-144, 2015. 
[8] H. Baudrand, M. Titaouine and N. Raveu, "The Wave Concept in Electromagnetism and Circuits: Theory and Applications," ISTE Ltd and John Wiley \& Sons In. August 2016.

[9] M. K. Azizi, L. Latrach, N. Raveu, A. Gharsallah, H. Baudrand, "A New Approach Of almost Periodic Lumped Elements Circuits By An Iterative Method Using Auxiliary Sources," American Journal of Applied Sciences. Vol. 10 No. 11, pp. 1457-1472, 2013.

[10] A. Salouha, L. Latrach, A. Gharsallah, A. Gharbi, And H. Baudrand, "Characterization Of Switchable And Multilayered FSS Circuits Using The WCIP Method," Int. Journal of Engineering Research and Applications, pp.109-116, November 2014.

[11] M. Latifa, L. Latrach, A. Gharsallah, "Analysis of an Almost Periodic Reconfigurable Circuits Using Iterative Method," International Journal of Applied Engineering Research. Vol. 11, No. 4, pp. 2508-2512, 2016.

[12] A. Zugari, N. Raveu, C. Girard, H. Baudrand, and M. Khalladi, "A Fast Hybrid WCIP and FDTLM Approach to Study Inhomogeneous Circuits," Progress In Electromagnetics Research C. Vol. 51, pp. 55-62, 2014

[13] S. Akatimagool, "Electromagnetic Software Tools for Microwave Multi-layer Integrated Circuits and Components," Journal of KMITNB. Vol. 13, No. 2, pp.7-11, Jun 2003.

[14] M. Titaouine, N. Raveu, A. G. Neto, "Dual-Band And Enhanced Band FSS Characterization Using WCIP Method," Microwave And Optical Technology Letters. 52, No. 4, pp. 836-839, April 2010.

[15] M. Titaouine, A. G. Neto, H.. Baudrand, and F. Djahli, "Analysis of Frequency Selective Surface on Isotropic/Anisotropic Layers Using WCIP Method,” ETRI Journal. Vol. 29, No. 1, pp. 36-44, February 2007.

[16] R. Gharbi, H. Zairi , H. Trabelsi, H. Baudrand, "Analysis of Complex Electromagnetic Structures by Hybrid FDTD/WCIP Method,” Journal of Electromagnetic Analysis and Applications. Vol. 4, pp. 497-503, 2012.

[17] M. Titaouine, A. G. Neto, H. Baudrand, and F. Djahli, "Determination Of Metallic Ring FSS Scattering Characteristics using Wcip Method," Microwave And Optical Technology Letters. Vol. 50, No. 5, pp. 1324-1328, May 2008.

[18] S. Aroussi, L. Latrach, N. Sboui, A. Gharsallah, A. Gharbi, H. Baudrand, "Efficient Analysis of Complex FSS Structure Using the WCIP Method," Journal of Electromagnetic Analysis and Applications, Vol. 3, pp. 447-451, 2011.

[19] G. A. J. Adaildo, G. Fontgall, M. Titaouine, H. Baudrand, H. M. D. Nóbrega,. A. G. Neto, "Analysis of Tapered Micostrip Patch Antenna by the Wave Concept Iterative Procedure," IEEE, pp. 61-66, 2009.

[20] A. G. Neto, J. C. Silva, J. N. Carvalho, A. N. d. Silva, C. B. d. Aguiar, F. M. Deisy, "Analysis of Frequency Selective Surface with U-Shaped Geometry," Journal of Microwaves, Optoelectronics and Electromagnetic Applications, Vol. 14, pp. 113-122, 2015.

[21] Jia-Sheng Hong, Lancaster, M.J. “Microstrip Filters for RF/Microwave Applications,” John Wiley \& Sons, Inc. 2001.

[22] I. Adoui, M. Titaouine, H. Choutri, A. Djouimaa, T. R. De Sousa, A. G. Neto, H. Baudrand, "Characterization Of Novel Open Notched Quasi-Square Metallic Ring FSS Using WCIP Method For Multiband Applications," Microwave And Optical Technology Letters, Vol. 58, No. 9, pp. 2071-2075, September 2016. 